\title{
A Closed Network Queue Model of Underground Coal Mining Production, Failure, and Repair
}

\author{
G. M. Lohman
}

(INAS-CR-157554) A CLOSED HET BORK QOEOE MODEI OF OHDEBGROUND COAL Profulsion Lab.)

FAILORE, AND EEPAIR (JEt PLOFOLSIOR CSCI 081

Auquist 15,1978

Prepared for

Bequartmont of Enirgy

by.

Jet Propulsion Latoration

Calfotota hasthute of Technology

Rasadena California

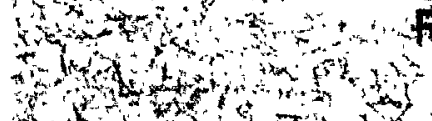

is
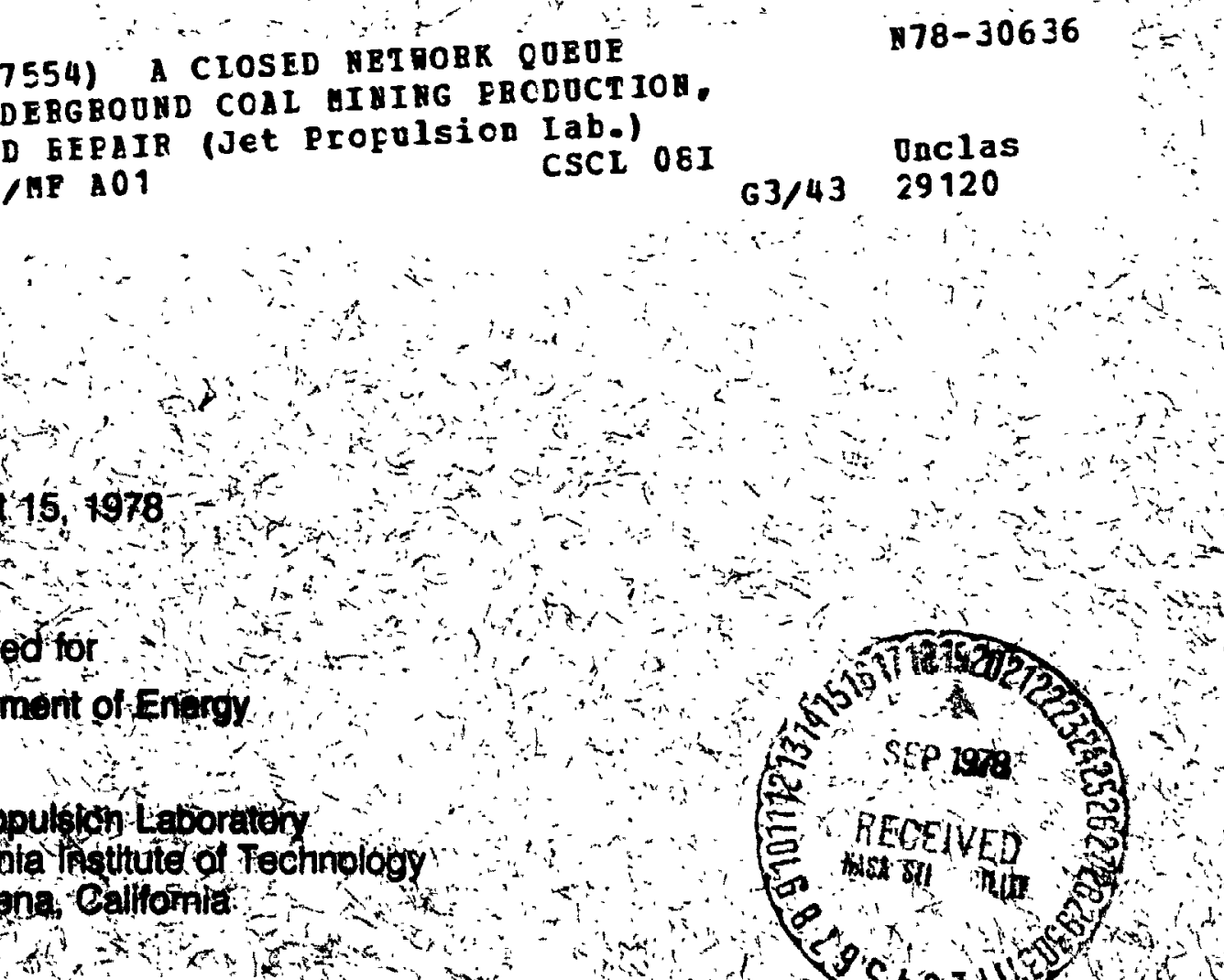

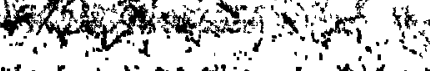

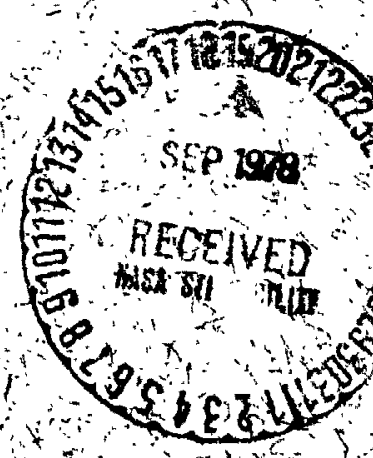


JPL PUBLICATION 78-72

\section{A Closed Network Queue Model of Underground Coal Mining Production, Failure, and Repair}

G. M. Lohman

August 15, 1978

Prepared for

Department of Energy

by

Jet Propulsion Laboratory

California Institute of Technology

Pasadena, Callfornia

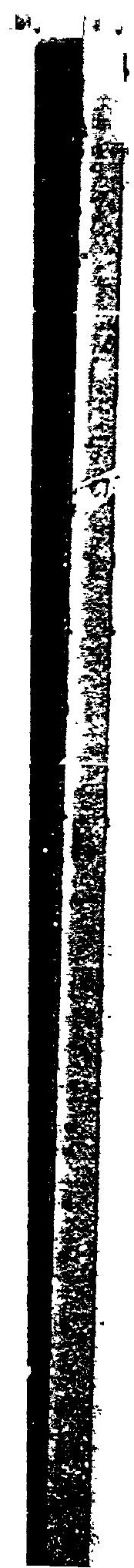




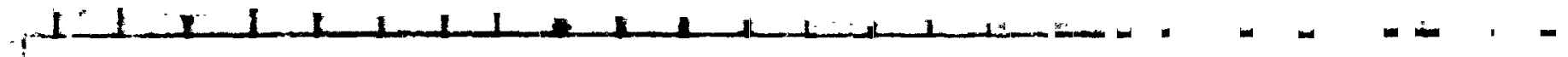

The remench deveribed in this publication was enrried out by the dex Propution Leboratory. Collfornis Inetitute of Technolosy. and wes sponeored by Depertment of Enerey throush en escoment with MASA. 
Underground coal mining systems production, failure, and repair cycles were mathematically modeled as a closed network of two quelies in series, in order to understand better the technological constraints on availability of current underground mining systems and to develop guidelines for estimating the availability of advanced mining systems and their associated needs for spares as well as production and maintenance personnel. 
Over the last e: iht years, underground coal mining productivity has dropped by almost 50\%, resulting in a parallel increase in the price of that cosi. Whatever the root causes of the productivity decline, it is an empirical fact that the avallability (fraction of time producing) of equipment at the working face is generally less than $75 \%$. Thus, the work presented in this report was undertaken with two objectives in mind:

- To understand better the technological constraints on the availability of current underground mining systems, and

- To develop guidelines for estimating the availability of advanced mining systems, and their associated needs for spares, as well as production and maintenance personnel.

The delays impacting avallability can be classified as occurring either predictably or randomly. Predictable delays may be accounted for using functional flow diagrams, but previous studies of random delays have been limited to statistical analyses of historical data or large simulations of specific mining technologies, rather than the development of analytical models with predictive cupability.

This report presents the construction and analysis of such a model. An underground mine is mathematically represented here as a collection of work. stations (sections) that a?ternately require servicing by one production crew and one repalr crew, each drawn from a respective pool of homogeneous crews. This interaction is modeled as a closed network of two queues in series, and is solved as a classical finite-state birth-and-death process. As such, the model is applicable to any cluster of processes that operate and fail independently, but which share pools of production and repair crews.

Sensitivity analysis of the model produces four major conclusions:

- The mean avallability of a section has a theoretical 1imit of $\rho /(1+\rho)$, where $\rho$ is defined to be the "maintainability ratio" of Mean Time Between Fallures (MTBF) to Mean Time to Repair (MTTR). Moreover, this theoretical limit will be achleved only when there are so many production and repair crews that seations never need to wait for either.

- Given a value for the malntainability ratio representative of current operacing experience, section avallability exhibits steep Improvement in response to small improvements in the maintainability rat10. Hence b 18 payoffs can be expected from concentrating efforts upon developing ways to incresse the time between fallures and/or decrease the tine to repalr fallures.

$\because$ The number of production crews should be 0.85 to 1.00 times the number of sections, and the number of repair crews should exceed the quotient of the number of production crews divided by the maintainability ratio, $p$. 
- The sensitivity of production at the mine mouth to the availability of any link in the haulage system is exactly equal to the quantity of coal that that link is expected to receive from all sections and haulage links feeding into it, times the availability of a11 haulage links between it and the mine mouth.

Key Words: Modeling, Energy, Coal, Underground Mining, Reliability, Production, Failure, MTBF, Equipment Utilization, Repair, MTTR, Network, Queue, Markov Process, Sensitivity Analysis. 


\section{ACKNOWLEDGMENTS}

The work reported here represents interim results from the Advanced Ccal Extraction systems Definition Project, a study performed at the Jet Propulsion Laboratory, Pasadena, California, for the Fossil Energy Program, United States Department of Energy, via an Interagenc' agreement with the National Aeronautics and Space Administration.

The author would like to take this opportunity to express appreciation for contributions made by several individuals. The continuing support of Mr. William B. Schmidt, Acting Director, Division of Solid Fuels Mining and Preparation, U.S. Department of Energy, is gratefully acknowledged. Mr. John Karhnak of the Division of Solid Fuels Mining and Preparation, Department of Energy, Mr. Charles Hayduk of the Carbondale Mining Research Center of the U.S. Bureau of Mines, and Mr. Charles Bickerton of Pennsylvania State University, all proved to be useful sources of information and industry data. Gerrie M. Hill of JPL provided the programing support for the sensitivity analysis. My colleagues on the coal team at JPL - espectally Messrs. W. Ronald Griffiths and Milton L. Lavin - supplied information, data, constructive review, and encouragement throughout the development of this model. Finally, I wish to thank Mrs. Elizabeth L. Foster and Mr. Erminio Gonzales of JPL for their expert preparation of this manuscript and its graphics, respectively, for publication. 
CONTENTS

A. MOTIVATION . . . . . . . . . . . . . . . . . 1

B. NOMENCLATURE .......................... . . 3

C. DEVELOPMENT OF THE MODEL FOR RANDOM FAILURES . . . . . . . . . . 7

D. ANALYSIS AND MODEL RESULTS . . . . . . . . . . . . . . . 12

E. CONSIDERATION OF HAULAGE AVAILABILITY . . . . . . . . . . . 14

F. SENSITIVITY ANALYSIS USING THE MODEL . . . . . . . . . . . . 16

G. CONCLUSIONS . . . . . . . . . . . . . . . . . 21

H. VALIDAtion . . . . . . . . . . . . . . . . . . 22

BIBLIOGRAPHY . . . . . . . . . . . . . . . . . . . 42

TABLES

1. Classification of Delays ................... 4

2. Historical Values of MTBF, MTTR, and . . . . . . . . . . 17

3. Nominal Values and Ranges of Input Parameters for Sensitivity

Analysis ...................... 18

\section{FIGURES}

1. A Closed Network of Two Multi-Server Queues ............ 9

2. Possible States and Transitions (with rates) of the $P$ Queue, for $\mathrm{m}=5, \mathrm{~s}_{\mathrm{P}}=4$, and $\mathrm{s}_{\mathrm{R}}=2 \ldots \ldots \ldots$

3. The Expected Number of Idle but Operational Sections (ENIOS) as a Function of the Ratio of Production Crews to Sections $\left(s_{p} / \mathrm{m}\right)$ for the Large Mine Case $\left(s_{R}=23, \rho=2\right) \ldots . . . \ldots . . . .$. .

4 The Expected Number of Idle but Operational Sections (ENIOS) as a Function of the Maintainability Ratio ( $(p)$ for the Small. Mine Case $\left(s_{p}-6, s_{R}=6, m-7\right) \ldots \ldots . . . . . . . . . .$.

3. The Expected Number of Idle but Operational Sections (ENIOS), Expected Number of Non-Operational Sectinas (ENNOS), and Total Idle Sectione as a Function of the Numbiser of Production Crews ( $\left.s_{p}\right)$ for the Large, Mine Case $\left(8_{R}-23, m=20, p-2\right), \ldots . . . . .$. . 
6. The Expected Number of Non-Operational Sections (ENNOS) as a Function of the Number of Repair Crews $\left(s_{R}\right)$ for the Poorly Balanced Case $\left(s_{\mathrm{p}}=16, \mathrm{~m}=16, \rho=2\right) . . . . . . . .$.

7. The Expected Number of Non-Operational Sections (ENNOS) as a Function of the Number of Sections (m) for the Poorly Balanced Case $\left(s_{P}=16, s_{R}=2, p=2\right)$ and the Small Mine Case $\left(s_{P}=6\right.$, $\left.s_{R}=6, p=2.5\right)$........................

8. The Expected Number of Non-Operational Sections (iNNOS) as a Function of the Maintainability Ratio $(\rho)$ for the Optimized Case $\left(s_{P}=18, s_{R}=8, m=20\right)$ and the Poorly Balanced Case $\left(s_{\mathrm{P}}=16, s_{\mathrm{R}}=2, \mathrm{~m}=16\right) \ldots \ldots \ldots$

9. The Expected Availability of an Average Section (US) as a Function of the Maintainability Ratio $(\rho)$ for the Optimized Case $\left(s_{\mathrm{p}}=18\right.$, $\left.s_{\mathrm{R}}=8, \mathrm{~m}=20\right)$. . . . . . . . . . . . . . . . . . .

10. The Expected Availability of an Average Section (US) as a Function of the Number of Production Crews $\left(s_{P}\right)$ for the Large Mine Case

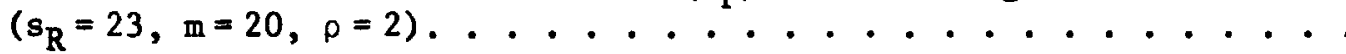

11. The Expected Avallability of an Average Section (US) as a Function of the Number of Repair Crews $\left(s_{R}\right)$ for the Large Mine Case $\left(s_{P}=18\right.$,

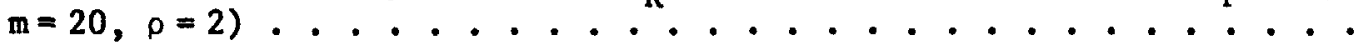

12. The Expected Availability of an Average Section (US) as a Function of the Number of Sections $\left(\pi_{1}\right)$ for the Small Mine Case $\left(s_{P}=6\right.$,

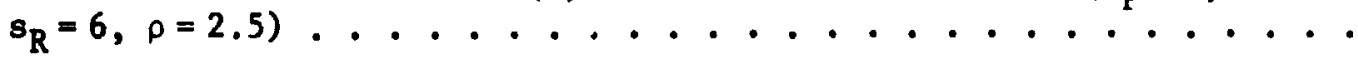

13. The Expected Utilization of Production Crews (UPC) as a Function of the Maintainability Ratio $(\rho)$ for the Optimized Case $\left(s_{p}=18\right.$,

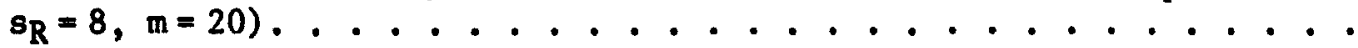

14. The Expected Number of Busy Production Crews (ENBPC) as a Function of the Number of Repair Crews $\left(s_{R}\right)$ for the Large Mine Case $\left(s_{p}-18\right.$, $\mathrm{m}=20, p=2) \ldots \ldots \ldots$

15. The Expected Utilization of Produition Crews (UPC) as a Function of the Number of Sections $(\mathfrak{m})$ for the Optimized Case $\left(s_{p}=18, s_{R}=8\right.$, $\rho=4)$ and the Poorly Balanced Case $\left(s_{P}=16, s_{R}=2, \rho=2\right)$....

16. The Expected Utilization of Production Crews (UPC) as a Function of the Number of Production Crews $\left(s_{P}\right)$ for the Optimized Case $\left(s_{R}=8\right.$,

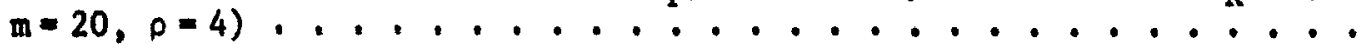

17. The Expected Utilization of Repair Crews (URC) as a Function of the Number of Repair Crews $\left(s_{R}\right)$ for the Optimized Case $\left(s_{p}=18\right.$, $\mathrm{m}=20, p=4) \ldots \ldots \ldots$ 
18. The Expected Utilization of Repair Crews (URC) as a Function of the Maintainability Ratio $(\rho)$ for the Optimized Case $\left(s_{P}=18\right.$, $\left.\mathrm{s}_{\mathrm{R}}=8, \mathrm{~m}=20\right)$. . . . . . . . . . . . . . .

19. The Expected Number of Busy Repair Crews (ENBRC) as a Function of the Number of Production Crews $\left(s_{p}\right)$ for the Small Mine Case

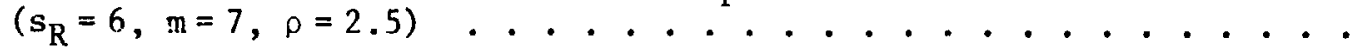

20. The Expected Number of Busy Repair Crews (ENBRC) as a Function of the Number of Sectjons $(m)$ for the Sma11 Mine Case $\left(s_{P}=6\right.$, $\left.s_{R}=6, \rho=2.5\right) \ldots . . \ldots \ldots$ 


impact on overall availability is derived. The sensitivity of mine performance to personel, seciions, ana equipment maintainability is discussed in detail in Section F. Finally, the conclusions obtained from this analysis are summarized n Section G, and suggested validation procedures are briefly presented in Section $\mathrm{H}$.

\section{NOMENCLATURE}

Before proceeding with development of the model, it is useful to define tatus of equipment.

Mine Terms called sections, each with its own complement of mining components such as a mines a portion of the cuts, the exact definition of which depends upon the method of nining. tion crew will perform minor repairs. Sections also of ten shan a common convers, rail lines, Classification of Down Time For the purposes of predicting the a lare degree, the predictability of a particular delay bv che nature of its cause. Hence the classification of delays shriwn in Table s primarily by cause, often delays such as preventive maintenance or safety eatings that can be scheduled, and which might otherwise occurs unexpectedly. somewhat subjective.

\section{Predictable Stoppages} mining system: travel time, lunch breaks, safety meetings, cire drilis, etc. unch breaks almost always are 30 minutes, and travel time is a function of the strative, but, unlike administrative delays, anagement and occur much less frequently. 


Reliability is the ratio of operational time to face time, i.e., the fraction of face time that the mine/section/component is not delayed by equipment failures.

Availability is the ratio of up time to face time, i.e., the fraction of face time that the mine/section/component is producing coal.

Utilization of a mine/section/component is the ratio of up time to clock time. Caution: this ratio is also sometimes referred to as availability.

Maintainability is the ratio of the mean time between failures to the mean time to repair, and indicates the mine's/section's/component's ability to keep operational and to get operational quickly when it fails.

\section{DEVELOPMENT OF THE MODEL FOR RANDOM FAILURES}

The remainder of this report presents the derivation, analysis, and results of a mathematical model to project section and mine down times, due to random failures (unpredictable delays) of sections making up the mine. Actually, the model developed below has much wider applicability. It can be applied to any cluster of processes that operate and fail independently, while sharing pools of production and repair crews.

First consider any section within the mine during normal production. It is assumed that each section has a full complement of equipment necessary to mine coal. The major equipment for a single section is difficult to move and essentlally configured in series. Hence, whenever one major component fails, the entire section fails and must he repaired [JPL II,L\&S; JPL III], because the bulkiness of the components effectively prohibits replacing the failed equipment with spares from an equipment nn:1- or from another section. lnstead, the production crew may be switched from the failed section to an operational section until a repair crew can get the equipment on the failed section operational again.* When the section is repaired, the repair crew moves on to the next section needing repair (if any), and a production crew, when avallable, will resume production on the repaired section.

It is assumed that each section fails independently of other sections, and only while in the process of production. Failures affecting all sections, such as a stoppage of a haulage system common to all sections, can be handled by treating the main haulage system as one component in a two-component sories system, the second component being the aggregation of all sections feeding into that main haulage system (see Section E).

To further simplify the model, it is assumed that the equipment on each section of the mine has the same average performance, so that identical crews

\footnotetext{
* In practice, crews are moved only when the repair time is expected to be of sufficiently long duration, so the avallability calculated below will not include the small amount of delay caused by the production crew waiting for completion of such small repairs. See also the discussion in Section $H$.
} 



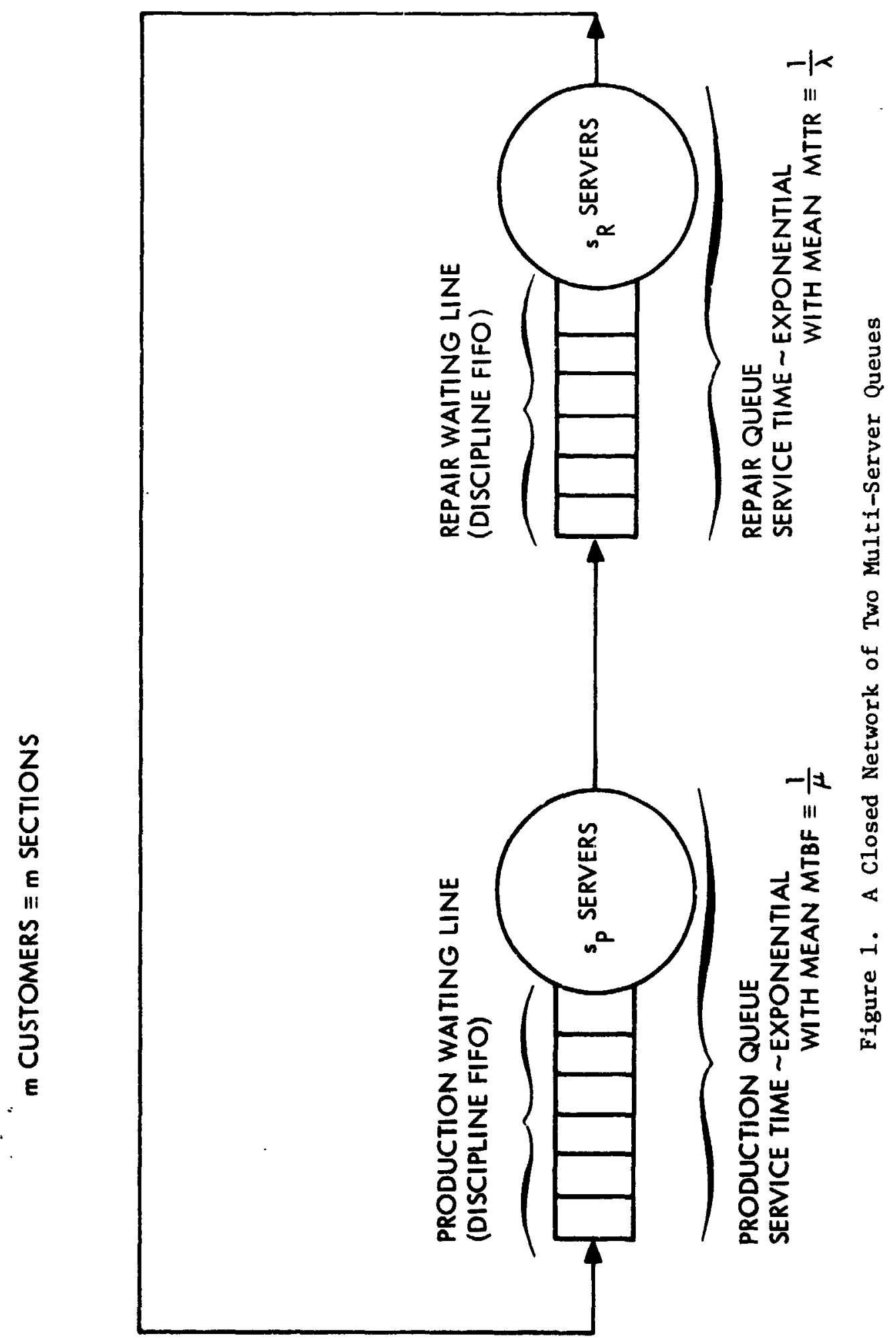


If one makes an additional assumption that service times are distributed exponentially, then the state of the network can be described by a Markov process, for which many useful results are known. The assumption of exponentially distributed service times is quite cormon and has been verified for many different fallure and repair processes under normal, steady-state operation.

As in any Markov process, the states to which the system can next move, and the rates at which it may go to those states, is a function only of the current state. The possible state transitions and their associated rates are best visualized schematicaily via an example. Suppose for illustrative purposes that $m=5, s_{p}=4$, and $s_{R}=2$. Then the system has six possible states: 0 up to 5 sections in the $P$ queue. Each of these states is shown as a circle in Figure 2, with arrows showing the transitions, and the numbers along arrows being the instantaneous rates of transition for this example. Examination of Figure 2 indicates the system can go from state 3 to state 2 at rate $3 \mu$, because only three of the four $P$ crews are busy when there are three sections in the $P$ queue, so only three $P$ crews are suffering fallures at rate $\mu$. And being in state 3 also implies that two sections are in the $R$ queue, with both undergoing repair at rate $\lambda$; hence trausition to state 4 (completion of the repair of one section and its return to the $P$ queue) is occurring at rate $2 \lambda$.

This process is a classical birth-and-death process, with state-dependent transition rates. In general, the rate of "birth" (arrivals from the $R$ queue to the $P$ queue) when in state $i$ is denoted by $\lambda_{i}(i=0,1,2, \ldots, m-1)$, and the rate of "death" (departures from the $P$ queue to the $R$ queue) when in state $i$ is denoted by $\mu_{1}(i=1,2, \ldots, m)$. Calculation of the transition rates in the manner described above yields the following general results:

$$
\begin{aligned}
& \left(\begin{array}{lll}
s_{R} \lambda & 0 \leq i \leq m-s_{R} & \text { (repair crews all busy) }
\end{array}\right.
\end{aligned}
$$

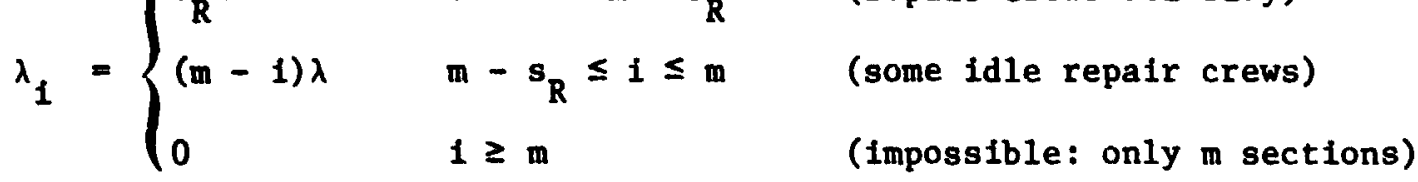

$$
\begin{aligned}
& =\lambda \min \left\{s_{R}, m-1\right\} \text {, for } 0 \leq 1 \leq m-1 \text {, and } \\
& \mu_{1}=\left\{\begin{array}{lll}
1 \mu & 1 \leq 1 \leq s_{p} & \text { (some production crews idle) } \\
s_{p} \mu & s_{p} \leq 1 \leq m & \text { (all production crews busy) } \\
0 & 1 \geq m & \text { (impossible: only m sections) }
\end{array}\right. \\
& =\mu \min \left\{1, s_{p}\right\}, \text { for } 1 \leq 1 \leq m \text {. }
\end{aligned}
$$




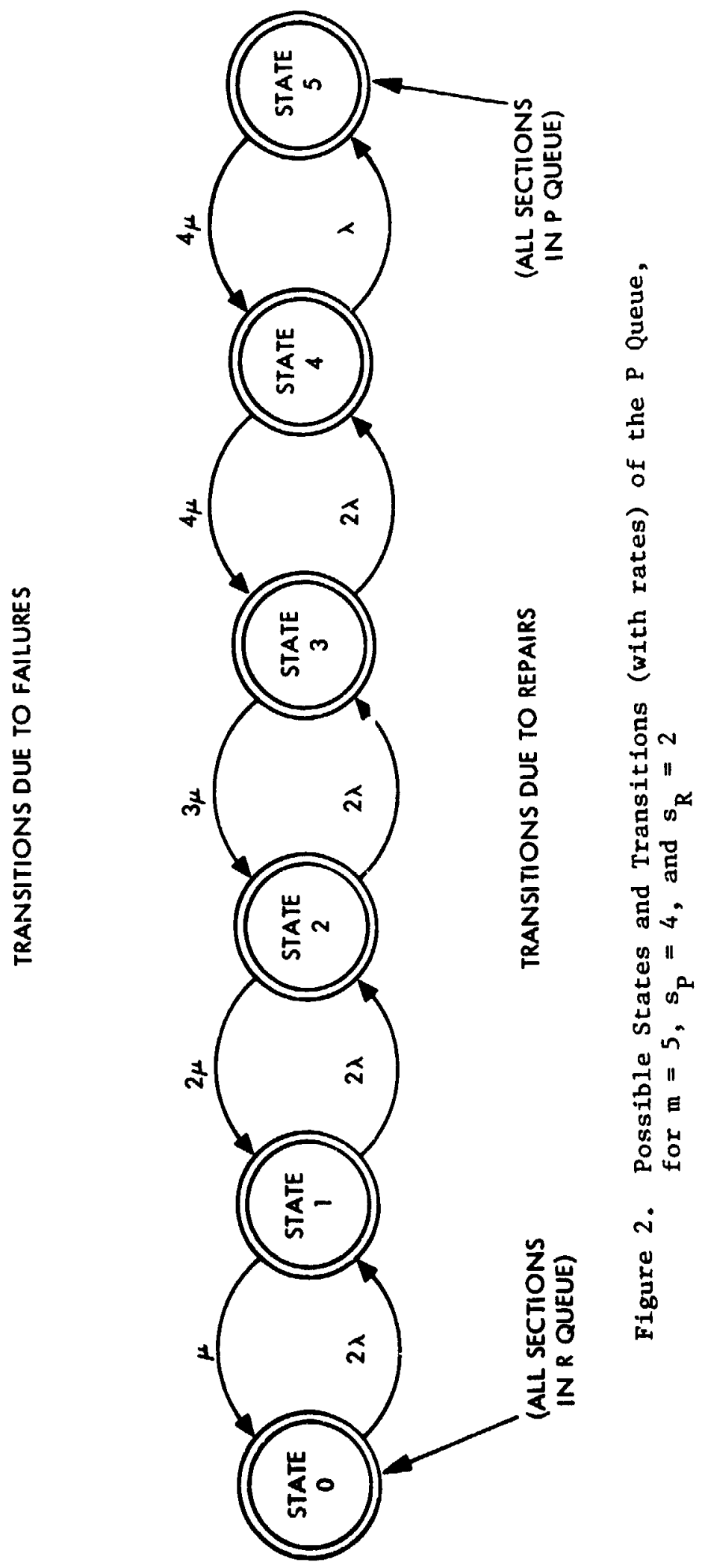


D. ANALYSIS AND MODEL RESULTS

The above definitions permit immediate use of the known results for a birth-and-death process. Bhat [Bhat], among others, has shown for a birthand-death process that the long-term (steady-state) probability, $\Pi_{1}$, of being in any particular state 1 , is

$$
\Pi_{0}=\left[1+\sum_{j=1}^{\infty}-\frac{\lambda_{1}{ }^{\lambda}{ }_{1} \cdots \lambda_{j-1}}{\mu_{1} \mu_{2} \cdots \mu_{j}}\right]^{-1}
$$

and

$$
\Pi_{i}=\frac{\lambda_{0} \lambda_{1} \cdots \lambda_{i-1}}{\mu_{1} \mu_{2} \cdots \mu_{i}} \Pi_{0}
$$

where the $\lambda_{i}$ and $\mu_{i}$ for this appiication are as given above.

Suppose for 1llustrative purposes that $s_{R} \leq s_{p}$, i.e., that production crews exceed repair crews. Then the probabilities $\Pi_{i}$ can be simplified to the recursive equations:

$$
\begin{gathered}
\pi_{i=} \frac{\min \left\{s_{R}, m-i+1\right\}}{\min \left\{i, s_{p}\right\}} \rho \pi_{i-1} \equiv c_{i} \rho^{i} \Pi_{0} \quad \text { for } i=1,2, \ldots, m \\
\pi_{0}=\left[1+\sum_{j=1}^{m} c_{j} \rho^{j}\right]^{-1}
\end{gathered}
$$

where

$$
\rho \equiv \frac{\lambda}{\mu}=\frac{\text { MTBF }}{\text { MTTR }} \text { and } c_{1} \equiv \prod_{j=1}^{1} \frac{\min \left\{s_{R} \cdot m-j+1\right\}}{\min \left\{j, s_{p}\right\}}
$$

These results are identical to those obtained by Rau [Rau]. 



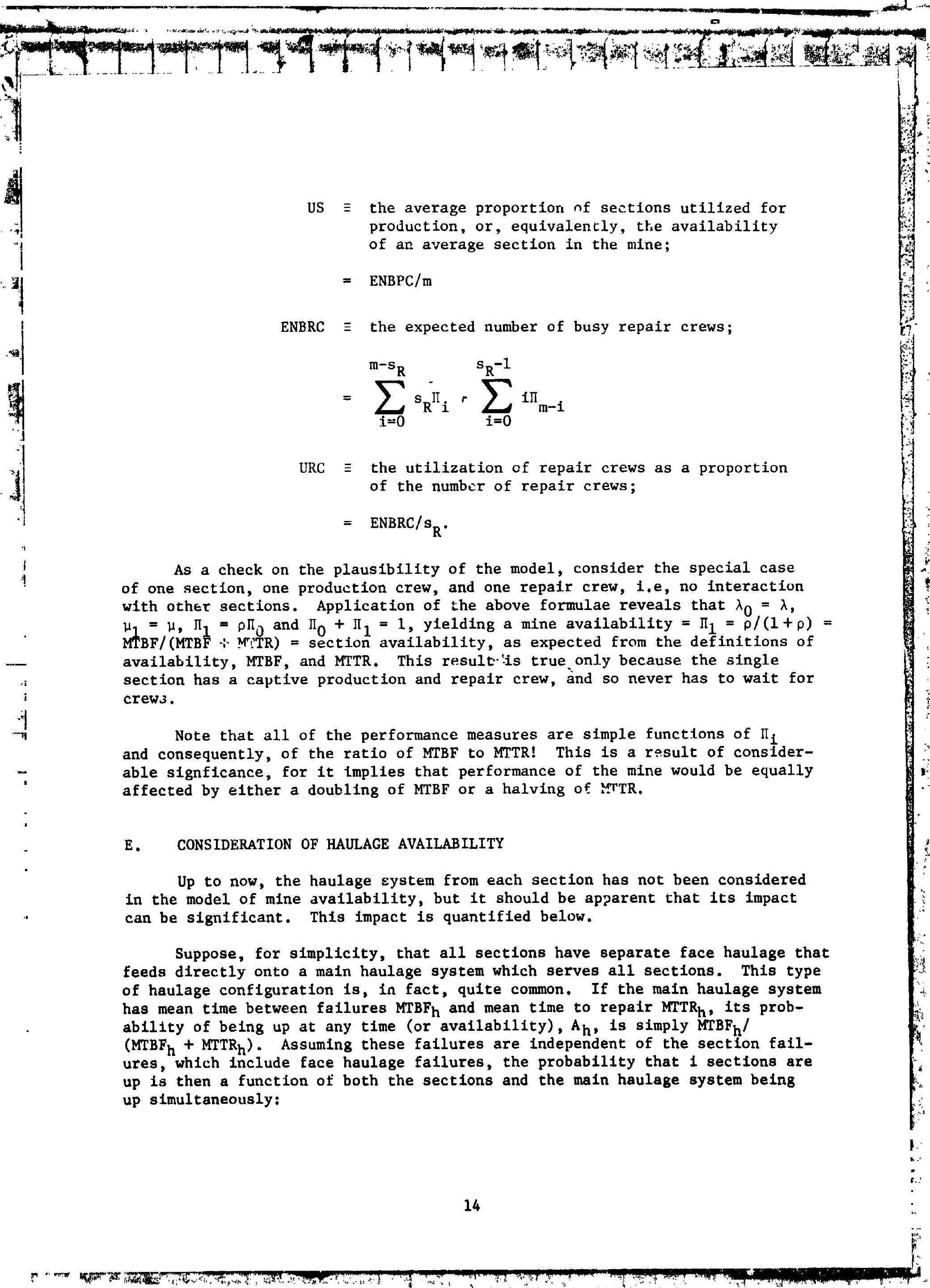





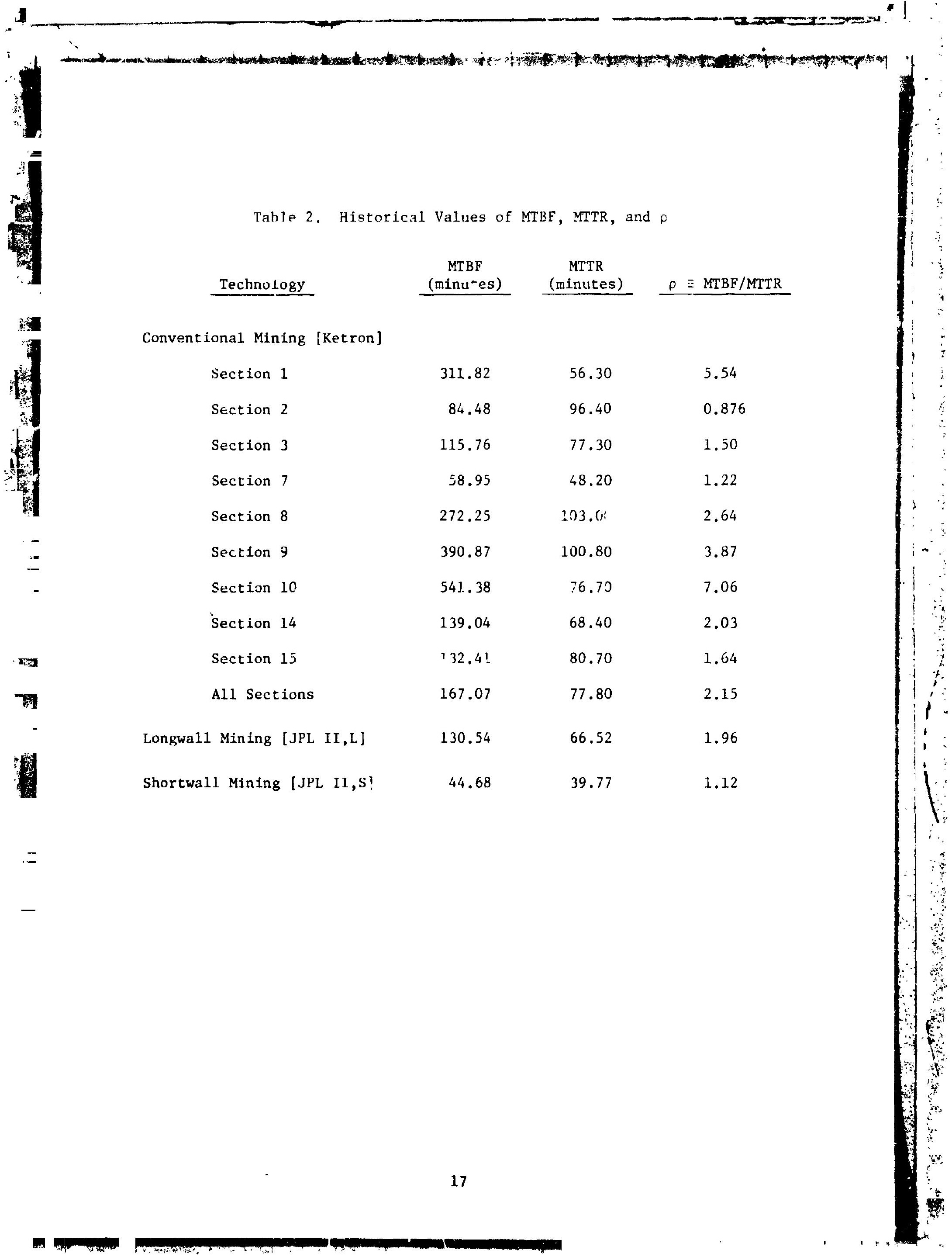




\begin{tabular}{|c|c|c|c|c|c|}
\hline \multirow{3}{*}{ 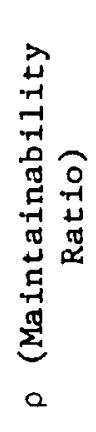 } & $\underset{\frac{\pi}{x}}{\dot{x}}$ & $\begin{array}{c}\stackrel{0}{0} \\
\infty\end{array}$ & $\stackrel{0}{\infty}$ & $\stackrel{0}{i}$ & $\begin{array}{l}0 \\
\dot{ \pm}\end{array}$ \\
\hline & $\underset{\dot{\Sigma}}{\stackrel{\dot{\Sigma}}{\Sigma}}$ & $\stackrel{0}{-}$ & ? & ? & ? \\
\hline & 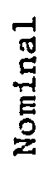 & $\dot{0}$ & $\stackrel{n}{\sim}$ & $\begin{array}{l}0 \\
\text { i }\end{array}$ & : \\
\hline \multirow{3}{*}{ 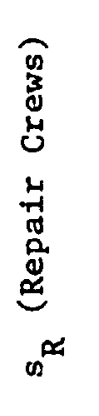 } & $\underset{\dot{x}}{\dot{x}}$ & ิㅗ & $\stackrel{ }{\circ}$ & $\stackrel{m}{m}$ & $\underset{-1}{g}$ \\
\hline & $\underset{\Sigma}{\stackrel{\vec{\Sigma}}{\Sigma}}$ & in & $N$ & -1 & -1 \\
\hline & 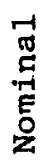 & $\stackrel{m}{\sim}$ & 0 & $N$ & $\infty$ \\
\hline \multirow{3}{*}{ 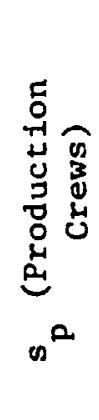 } & $\underset{\dot{x}}{\dot{x}}$ & $\stackrel{\sim}{\sim}$ & $\stackrel{\circ}{\circ}$ & $\vec{N}$ & $\stackrel{m}{m}$ \\
\hline & $\underset{\Sigma}{\dot{T}}$ & n & $N$ & in & in \\
\hline & 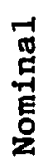 & $\stackrel{\infty}{\rightarrow}$ & 0 & $\underset{-1}{0}$ & $\stackrel{\infty}{\infty}$ \\
\hline \multirow{3}{*}{ 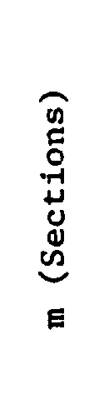 } & $\dot{x}_{\frac{\pi}{2}}^{\dot{\alpha}}$ & $\exists$ & $\stackrel{\circ}{\text { N }}$ & $\vec{\sim}$ & \& \\
\hline & $\underset{\dot{\Sigma}}{\dot{\Sigma}}$ & $\stackrel{\simeq}{\sim}$ & $N$ & in & $\underset{-1}{\sim}$ \\
\hline & 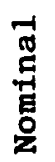 & 오 & $N$ & $\stackrel{r}{n}$ & $\stackrel{\ominus}{\sim}$ \\
\hline & 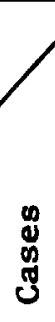 & 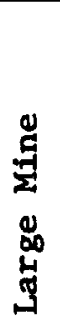 & 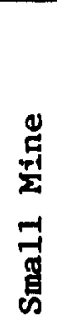 & 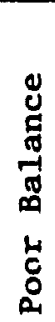 & 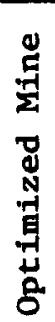 \\
\hline
\end{tabular}


Utilization of Sections (ENIOS, ENNOS, and US)

In a mine that has approximately 0.85 to 1.0 production crew per section, ENIOS is generally less than 0.01 ! ENIOS exceeds one section only when the ratio of production crews per section drops below two-thirds (Figure 3). Furthermore, this low value of ENIOS is virtually insensitive to $s_{R}$, so long as $s_{R}$ is adequate (see below). Comparison of these statistics against the expected number of non-operational sections (Figure 5) shows a higher idleness of sections due to failure than due to lack of production crews, for $s_{p}$ greater than $0.5 \mathrm{~m}$.

For a mine with good balance between sections and production crews, improving the maintainability of each section (i.e., increasing $\rho$ ) increases ENIOS with slightly increasing slope up to about $\rho=3.5$ in the small mine case, after which the slope decreases slightly (Figure 4). This change in slope occurs at larger $\rho(\rho \approx 7)$ for larger mines. In all cases, however, as $\rho$ increases, ENIOS is less than one-half section idled for values of $\rho$ below the maximum value of $\rho=7.06$ observed in the data available.

It may be concluded from the above observations that extra sections, and their associated equipment, will not be significantly idle if the ratio of production crews to sections is maintained between 0.85 and 1.0 , and sufficient repair crews are available. This conclusion applies without regard to the scale of operation, e.g., the sensitivities were identical for the small mine with seven sections and six production crews. The fundamental observation here is that an extra section or two will not go begging for production crews, if the crews are permitted to move to a new section rather than await the repair of a failed section.

In cases where repair crews are no problem (all but the poorly balanced case), ENNOS rises steeply with increasing $s_{p}$, then levels of $f$ in logarithmic fashion. It is asymptotic to $s_{p} / p$ over the approximate interval 0 to $0.6 \mathrm{~m}$, then bends over during the interval $0.6 \mathrm{~m}$ to $0.95 \mathrm{~m}$ in order to be asymptotic to $\mathrm{m} /(1+\rho)$ thereafter (Figure 5). This latter asymptote is in agreement with intuition, since $1 /(1+\rho)=$ MTTR/(MTR + MTBF) is the fraction of time an average section would spend under repair when there is no waiting for crews.

For the poorly balanced case,., however, where a shortage of repair crews forces considerable waiting in the repair ( $R$ ) queue, ENNOS is asymptotic to $3 / 4 \mathrm{~m} \quad(=12$ sections, considerably higher than the 5.33 sections predicted by $\mathrm{m} /(1+\rho))$. Confirmation of this sensitivity of ENNOS to the number of repair crews $\left(s_{R}\right)$ is shown by Figure 6 . ENNOS steeply decreases with increasing $s_{R}$, and appears to be the function $\mathrm{m}-\rho \mathrm{s}_{R}$, until about $0.25 \mathrm{~m}$ to $0.35 \mathrm{~m}$, after which it bends up to become asymptotic to $\mathrm{m} /(1+\rho)$ after about $0.5 \mathrm{~m}$. The graph shows that ENNOS is extremely sensitive to $s_{R}$ at the nominal value of $s_{R}=2$, and could be improved from 12 to the asymptote of 5.33 by increasing the number of repair crews to at least a less sensitive value like $s_{R}=7$. See also the section below on utilization of repair crews.

Sensitivity of ENNOS to $m$ is analogous to that of $s_{p}$. Again, in systems where repalr crew capacity is no problem, ENNi3 is an increasing linear function $\mathrm{m} /(1+\rho)$ when the system is section-constrained (small $\mathrm{m}$ ), leveling off 

$\rho$ times the: asymptote for ENNOS, as one would exp?ct (recall that $\rho /(1+\rho)=$ MTBF/(MTBF + MTTR) is the expected avallability oi a typical section in isolation, i.e., with no shortage of repair crews). Siullarly, as the numter of sections increases, for a fixed number of production crews, the production crews asyinptotically approach full utilization, except when repai- crew shortages linit the number of sections available for any number of product:or. crews to $\rho s_{k}$ as in the poorly balanced case (Figure 15). As with the : ec:ions, expected utilization of production crews (UPC) is asymptotically 1.0 when production crews are in short supply, then drops sharply when $s_{p}$ exceeds the minimum of either about $0.75 \mathrm{~m}$ or $s_{R}$, and finally starts to level of $f$ as poorer utilization levels are reached $(U P C<0.80)$. See Figure 16.

\section{Utilization of Repair Crews (ENBRC and URC)}

The utilization of repair crews (URC), asymptotically 1.0 whea repair crews are in short supply compared to the incidence of failures, makes the same sharp drop-off followed by leveling off for increasing values of both $s_{R}$ and $p$ (Figures 17, 18). In other words, utilization of repair crews will decrease dramatically if either the supply $s_{R}$, of repair crews increases, and/or the demand for those crews decreases due to a lirg:r value of $\rho$ (better maintainability).

As is the case for sections a..u production crews, utilization of rtpair crews improves sharply with additional production crews or sections until an "adequate" number are available, at which point a plateau in performance is reached (Figures 19,20$)$. For increasing $s_{p}$, the ENBRC curve is asymptotic to the minimum of $s_{R}$ and $m /(1+\rho)$, where $1 /(1+\rho)$ is the expected proportion of time that a section with no shortage of production crews is in the $R$ queue. For increasing $m$, the ENBRC curve is asymptotic to the minimum of $s_{R}$ and $s_{p} / p$.

\section{G. CONCLUSIONS}

Four major conclusions can be derived from the above analysis:

(1) Mine performance is theoretically limited by the maintainability rat1o, $\rho=$ MTBF/MTTR, even when the number of crews and sections are well balanced. In particular, the expected avallability of an average section will not exceed $\rho,(1+\rho)=M$ MBF/(MT:F + MTTR). Furthermore, availability will only achleve this level when there is a sufficient number of production and repair crews such that sections never need to wait for either, which usually implies costly idle time for these crews.

(2) Based upon current industry experience, significant gains in avail-ability appear possible by means of small improvements in the time between failures and/or the time to repair failures. The historical data of Tabla 2 indicates that many existing mines for which figures are available have a maintainabllity ratio between 1 and 2.6 . Within this range, all performance neasures exhibit steep improvement when small improvements are made in the malntainability ratio, $\rho$, and are still far from the region of diminishing returns (bes Figures 8, 9, 13). Big payoffs can, therefore, be expected from Increases in the time between fallures and/or decreases in the time to repair 
failures. Hence, research should concentrate on ways to make equipment run longer between failures and/or easier and quicker to repair. Equipment design can facilitate the second objective by providing better service accessibility, modular design and a sufficient inventory of spare modules, completely interchangeable parts, simpler mechanisms, and lighter, more mobile equipment. The first objective would also be aided by simpler machinery, as well as more durable materials, quality control and testing, built-in redundancy in critical components, governors or monitors to prevent over-stressing of equipment, and preventive maintenance tailored to the history of an individual com ntat. It should be noted that, unless properly designed, technologies which are more altomated may even regress on both objectives, due to their noteritially more complex, heavier, less mobile, and as yet unproven mechanisms [JPi $I I, L]$.

3) The number of crews and sections should be proporly balanced for any given maintainability ratio, $\rho$. Specifically, the number of production crews ( $s_{p}$ ) should be 0.85 to 1.0 times ciar number of sections (m); the number of repair crews should be at least $s_{p} / \rho$, where $\rho=M T B F / M T T R$. Addition of sections, repair crews, or production crews beyond this balance can only decrease utilization of similar entities, and utilization Jf dissimilar entities will not be significantly improved because of their already near-saturated use. Note especially that a change in the maintainability ratio necessitates a reevaluation of the number of repair crews required.

(4) Main haulage systems closest to the mine mouth require the most attention to rellability. In general, the sensitivity of mine mouth produrtion to the availability of any link in the haulage system is exactly equal to the quantity of coal it is expected to receive from all sections and haulage links feeding into it, times the availability of all haulage links in line between it and the mine mouth. Thus if a reliability choice must be made between two otherwise equal face haulage systems, each serving one section, the face haulage system serving the section having the greater overall production per hour (i.e., including availability) should receive priority.

\section{H. VALIDATION}

Imnediate validation of much of the above model, unfortunately, is not currently practical. There is a surprising scarcity of non-proprietary data on performance before and after changes in the number of crews, sections, and/or $\rho$ have been made to a single mine, although at least one study of this is under way [Hayduk]. Experiments to verify the model must be performed on a single mine, in order to ensure that geological differences do not affect the results. Ideally, only one of the input parameters required by the model would be varied. Possible variations include:

- Increasing or decreasing the number of production or repair crews

- Opening a new section of the mine

- An alteration of equipment or maintenance management policies that changed the equipment's MTBF and/or MTTR 
- Switching mining methods from, say, conventional to longwall, possibly accomplishing all of the above.

Only the beginning and duration of each idle period for each production and repair crew need be observed. Calculation of the proportions of time that $0,1,2, \ldots, m$ sections were actually busy, and comparison of those predicted by the $\Pi_{i}$ of the model, would then be stralghtforward. At a minimum, actual availabilities, before and after the input parameters are changed, should be observed and compared.

of course, a prerequisite of validation is locating a mine satisfying the majority of the model's assumptions. Because this was a top-level, analytical model, many of the little realistic details that might be incorporated into a large computerized simulation were assumed away. Such simplification allows more exhaustive sensitivity analysis at little marginal cost, but makes the choice of a representative mine and correct definition of input values more critical. For example, in many mines the size and makeup of repair crews is varied according to the severity of the failure and/or the availability of company experts on certain types or failures, such as hydraulic engineers. Some mines assign a mechanic to each production crew to repair minor failures. In these cases, late in a shift, or when hauling coal out of the mine saturates limited transportation routes, production crews do odd jobs on that section rather than move to another section when a failure occurs. Failures of replicated components such as shuttle cars or scoops may not always cause section production to cease altogether, unless all replicates fail simultaneously, or one blocks production by faiting in a strategic location. The impact upon the model of these details has yet to be determined.

Some of the conclusions, however, have been substantiated by industry practice. In particular, there exists some evidence that, by trial and error, existing mines have balanced crews and sections in agreement with the rules of thumb suggested by the sensitivity analysis using the model. For example, one mine in Pennsylvania with a MTBF $=9$ hours and a MTTR $=1.18$ hours operates five sections with only three production crews and one maintenance crew, resulting in a measured availability of $80 \%$ [Hayduk]. The rules of thumb given above would suggest $(0.85)(5)=4.25$ production crews and $4.25 / 7.63=0.55$ repair crews, which when rounded off is only off by one production crew. Another mine, in Kentucky, operates seven sections with six production crews and six repair crews. If the postulated value of $\rho=2.5$ for this mine is accurate, the rules of thumb indicate it could save money by reducing its repair crews from six to two without significantly affecting production. The assignment of six production crews to the seven sections is in exact agreement with the derived relationship of 0.85 production crew per section. Similarly, the conclusions that main haulage systems and MTBF/MTTR are critical to improving avallability are already -intultively understood by most mine engineers; the sensitivity analysis serves to isolate and quantify the extent of their impact so that more rigorous cost trade-offs can be performed for particular instances. 


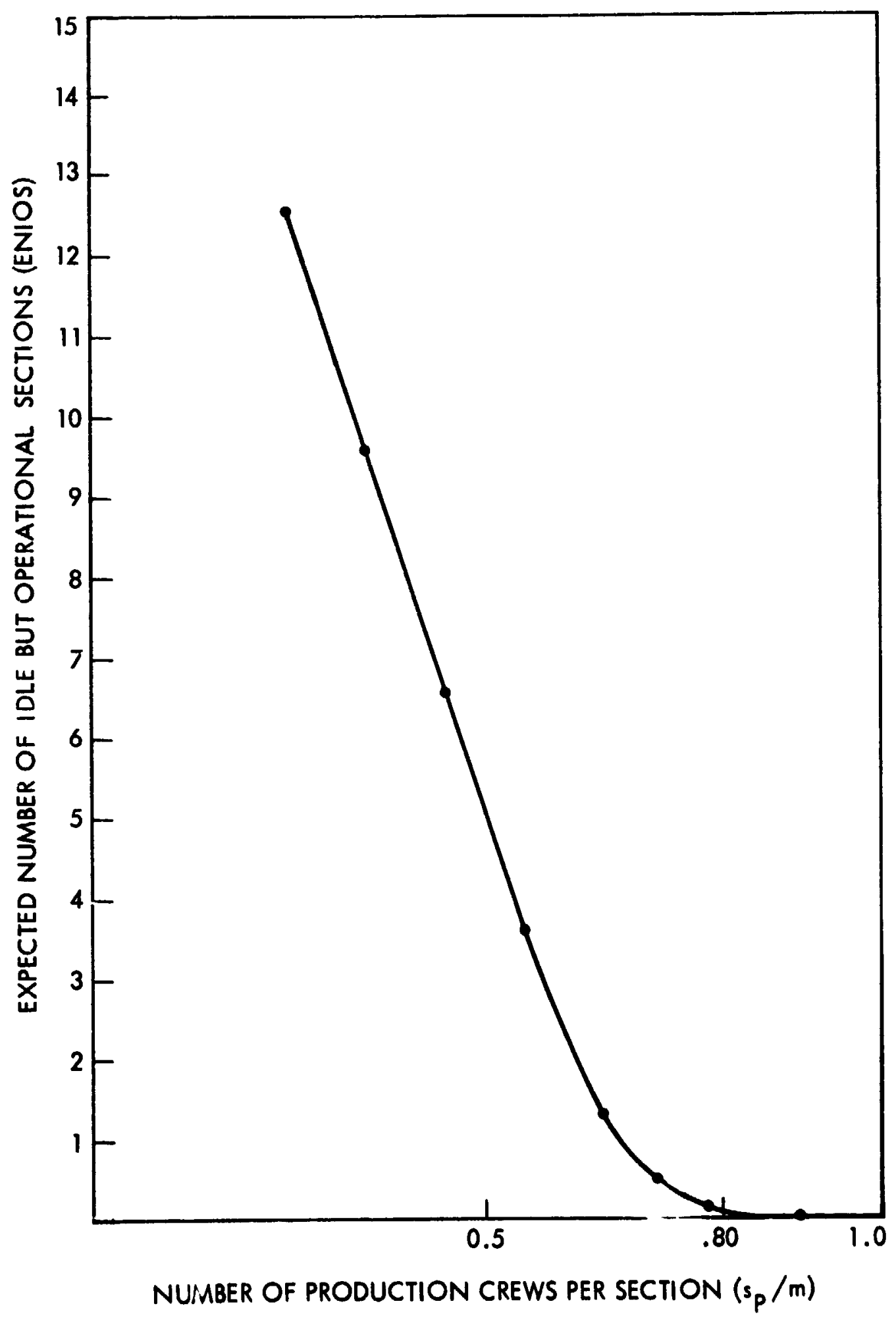

F1gure 3. The Expected Number of Idle but Operational Sections (ENIOS) as a Function of the Ratio of Production Crews to Sections $\left(s_{p} / m\right)$ for the Large Mine Case $\left(s_{R}=23, p=2\right)$ 


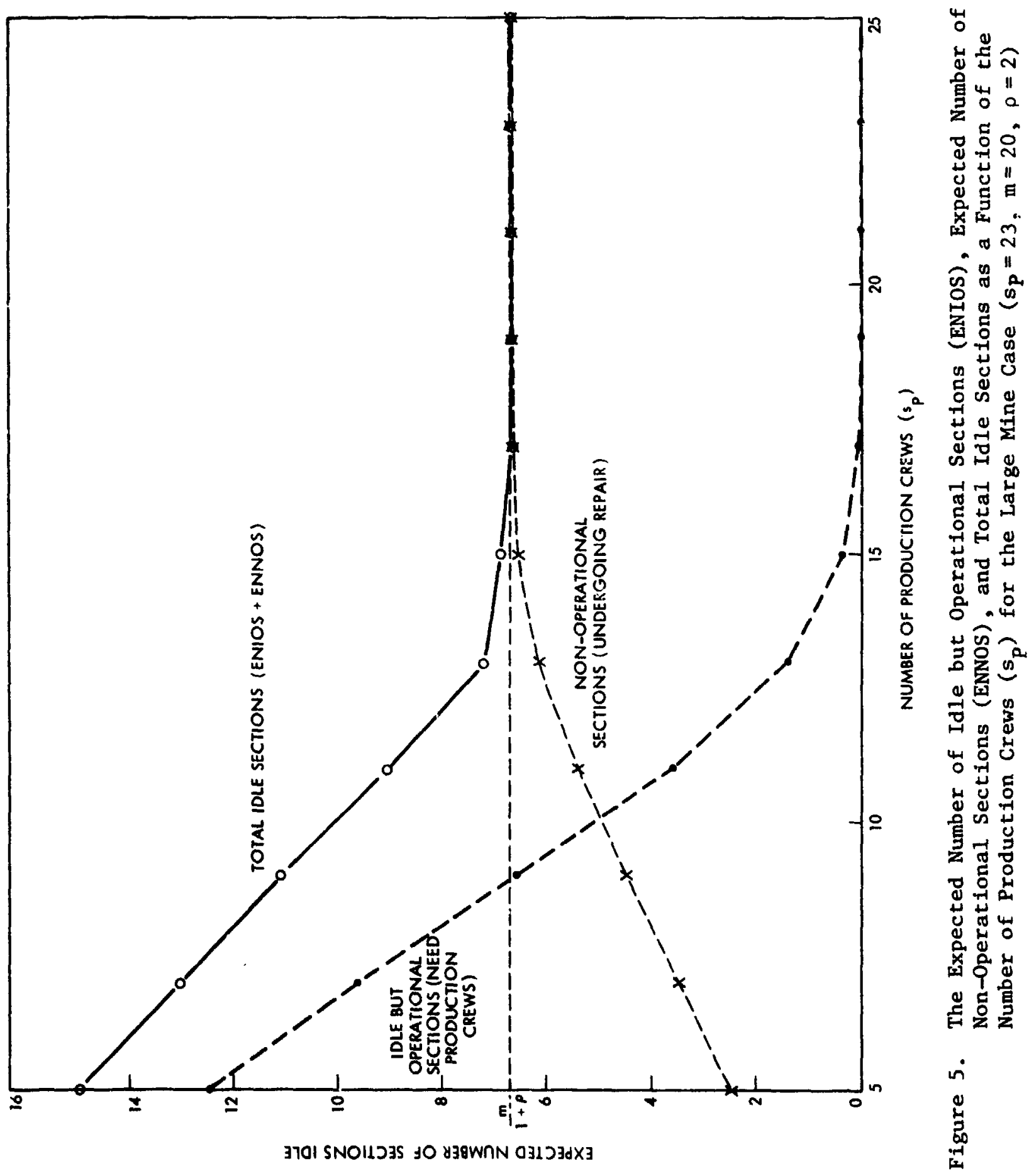




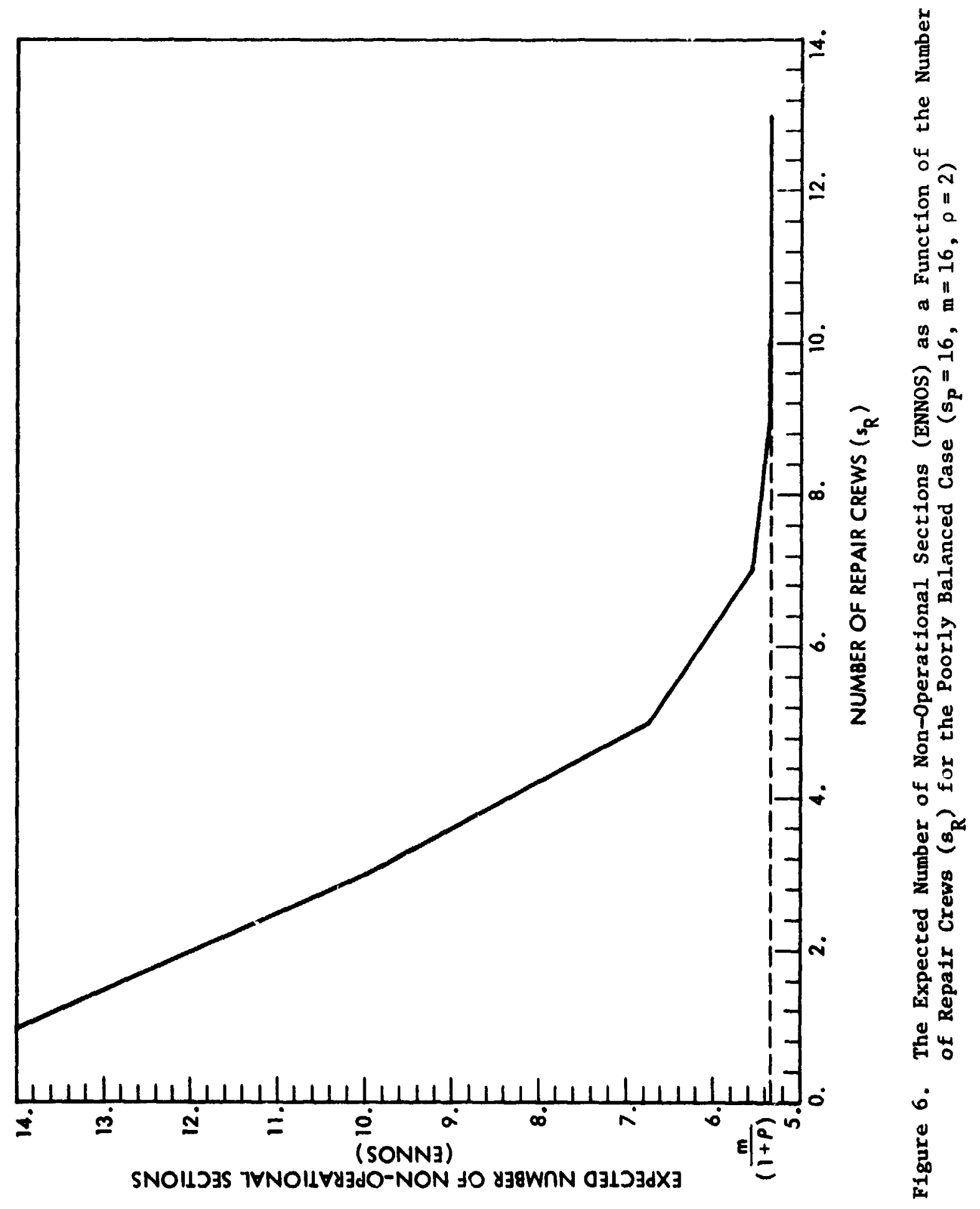




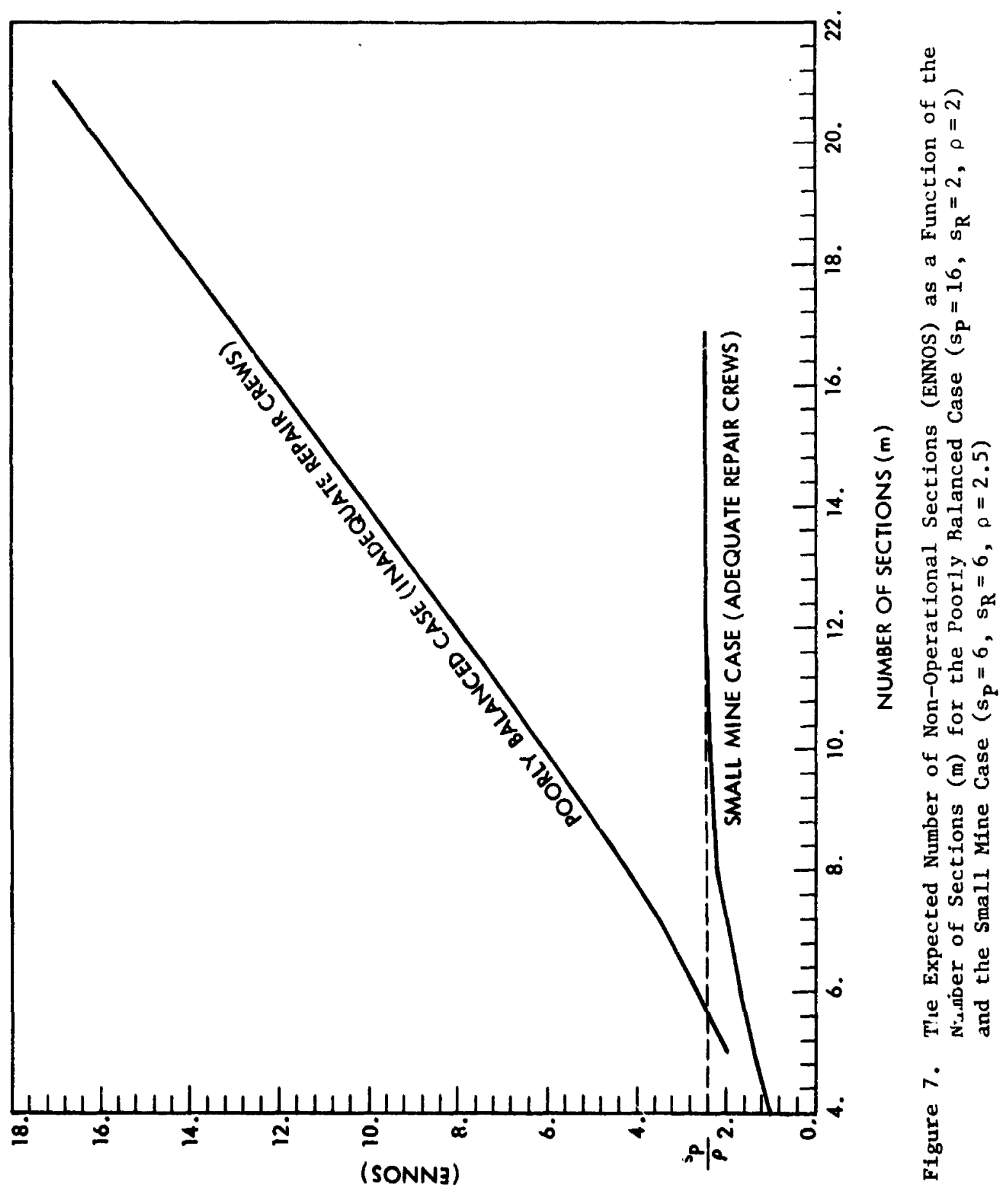

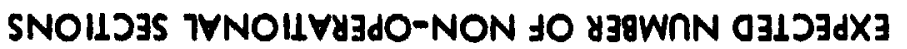




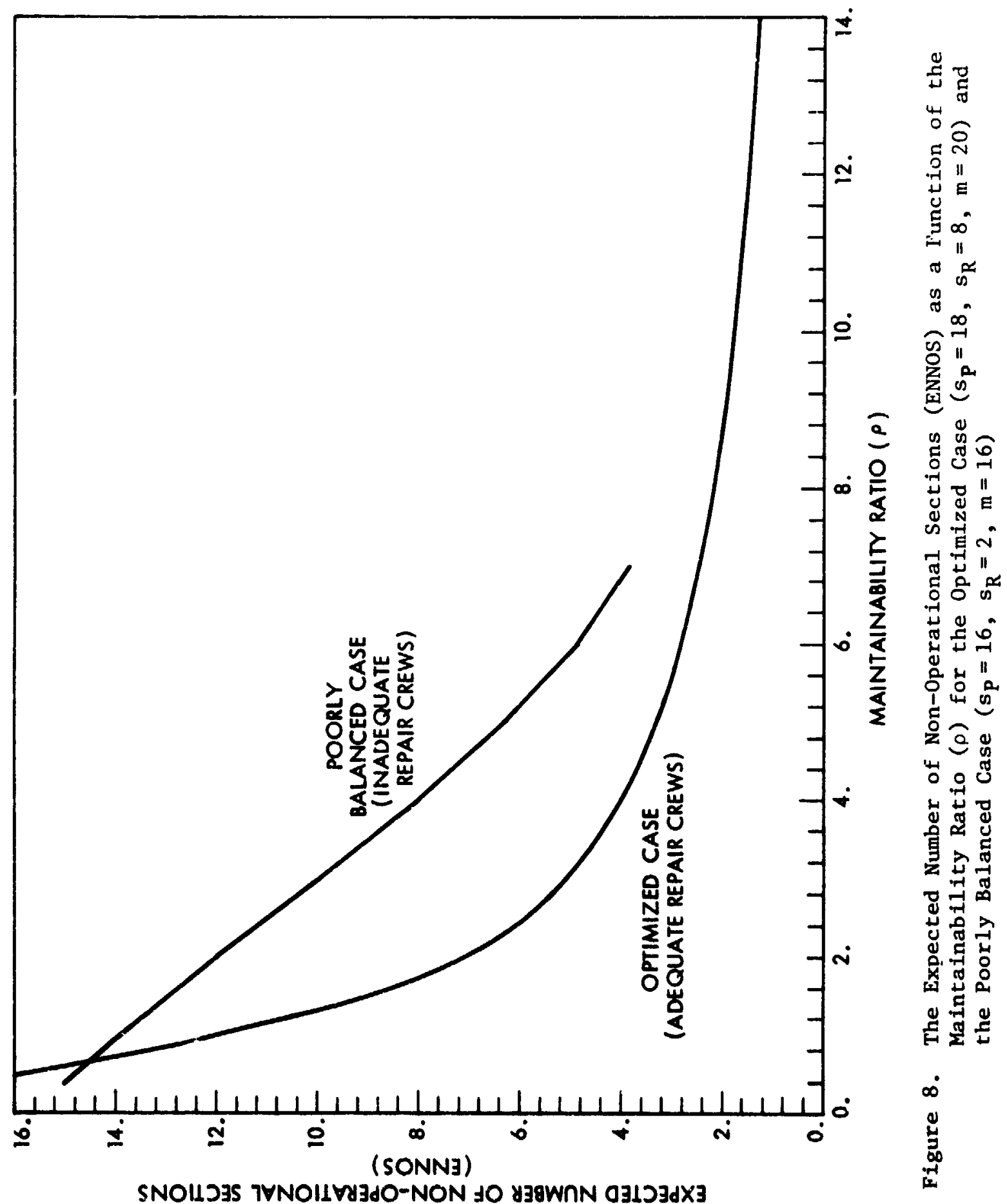




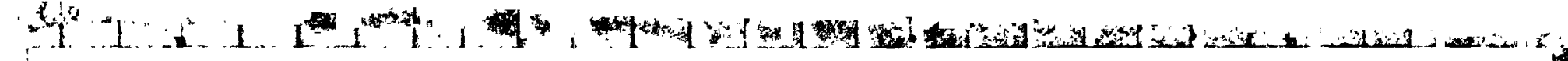
(1)

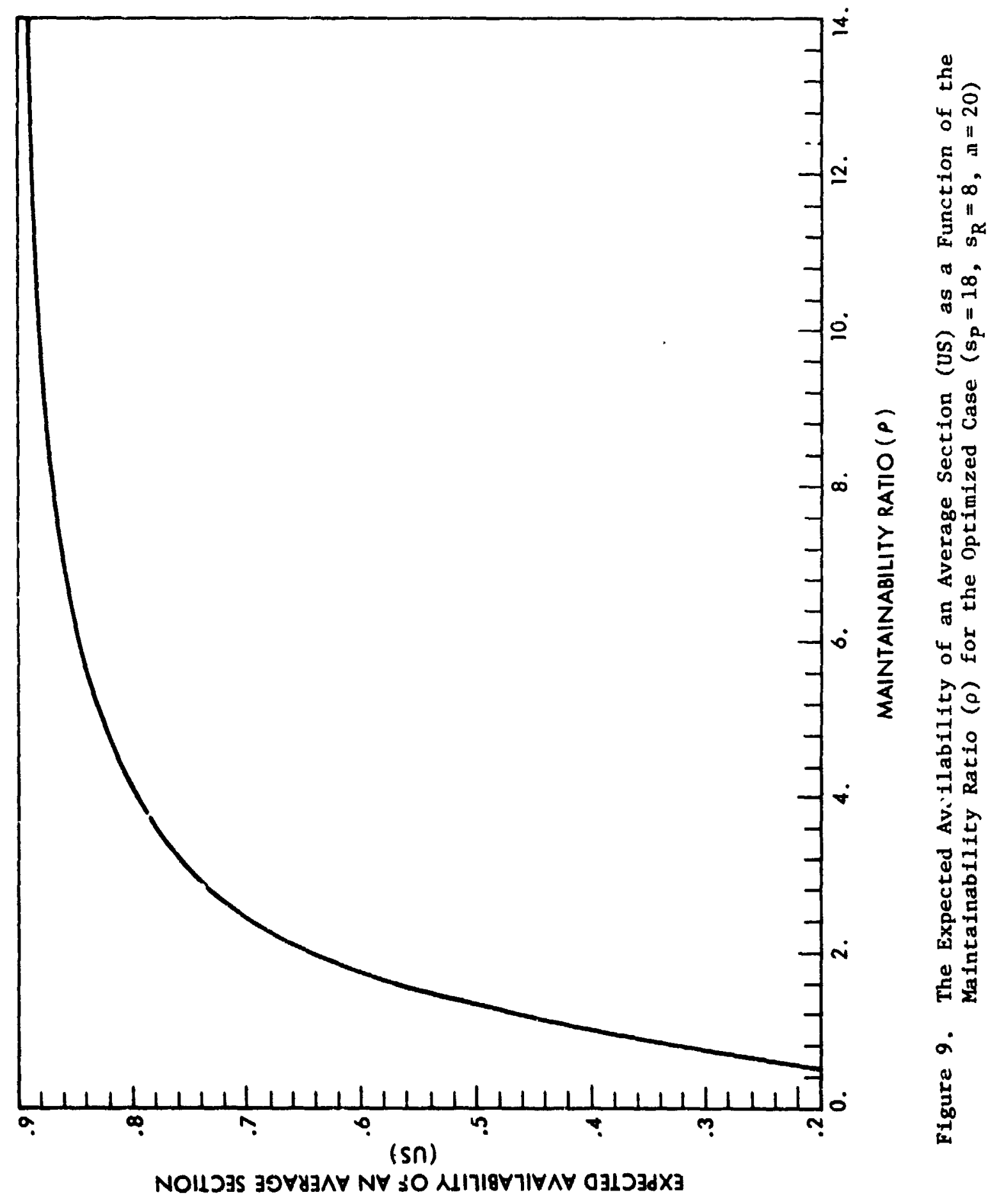



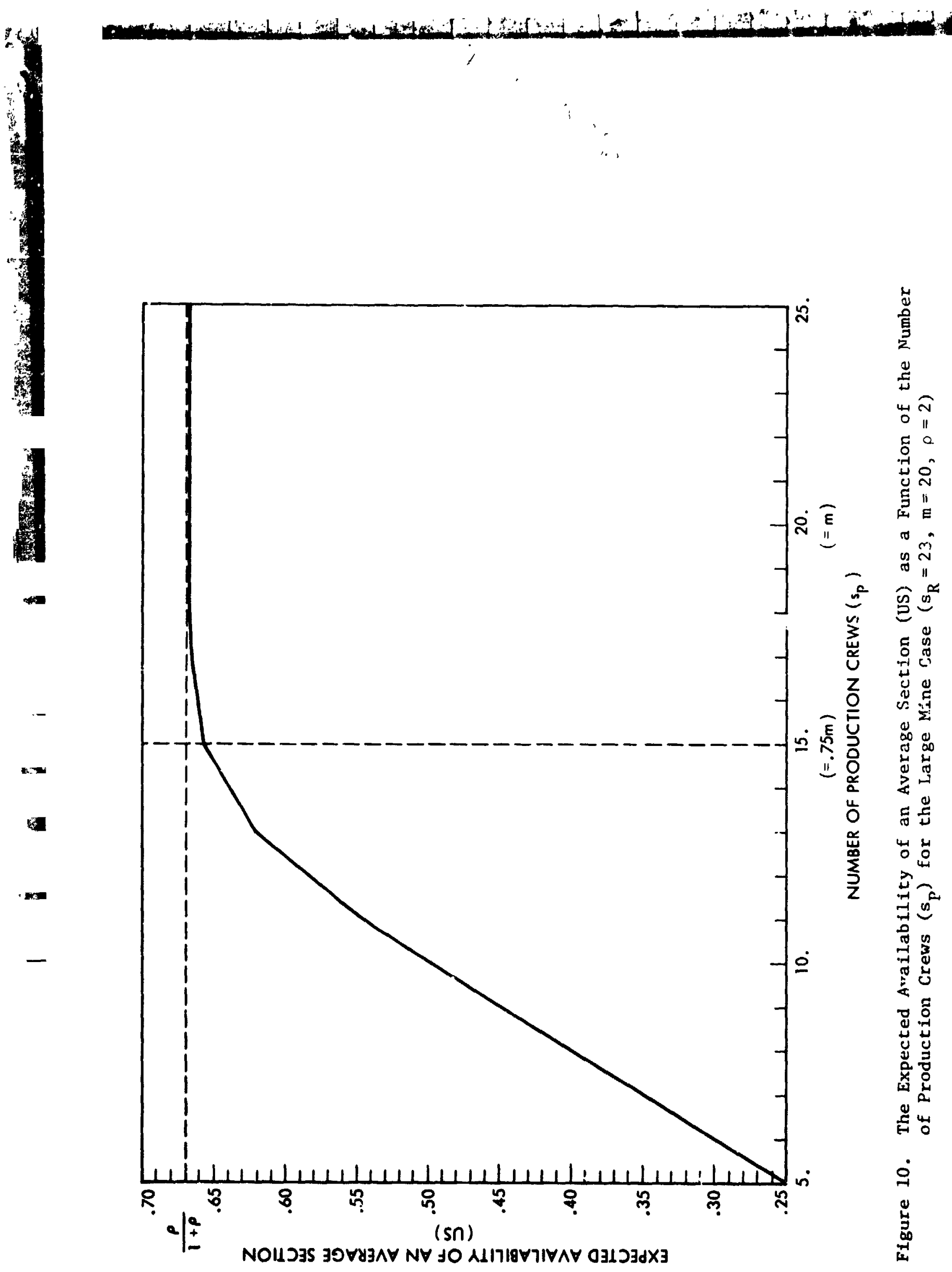


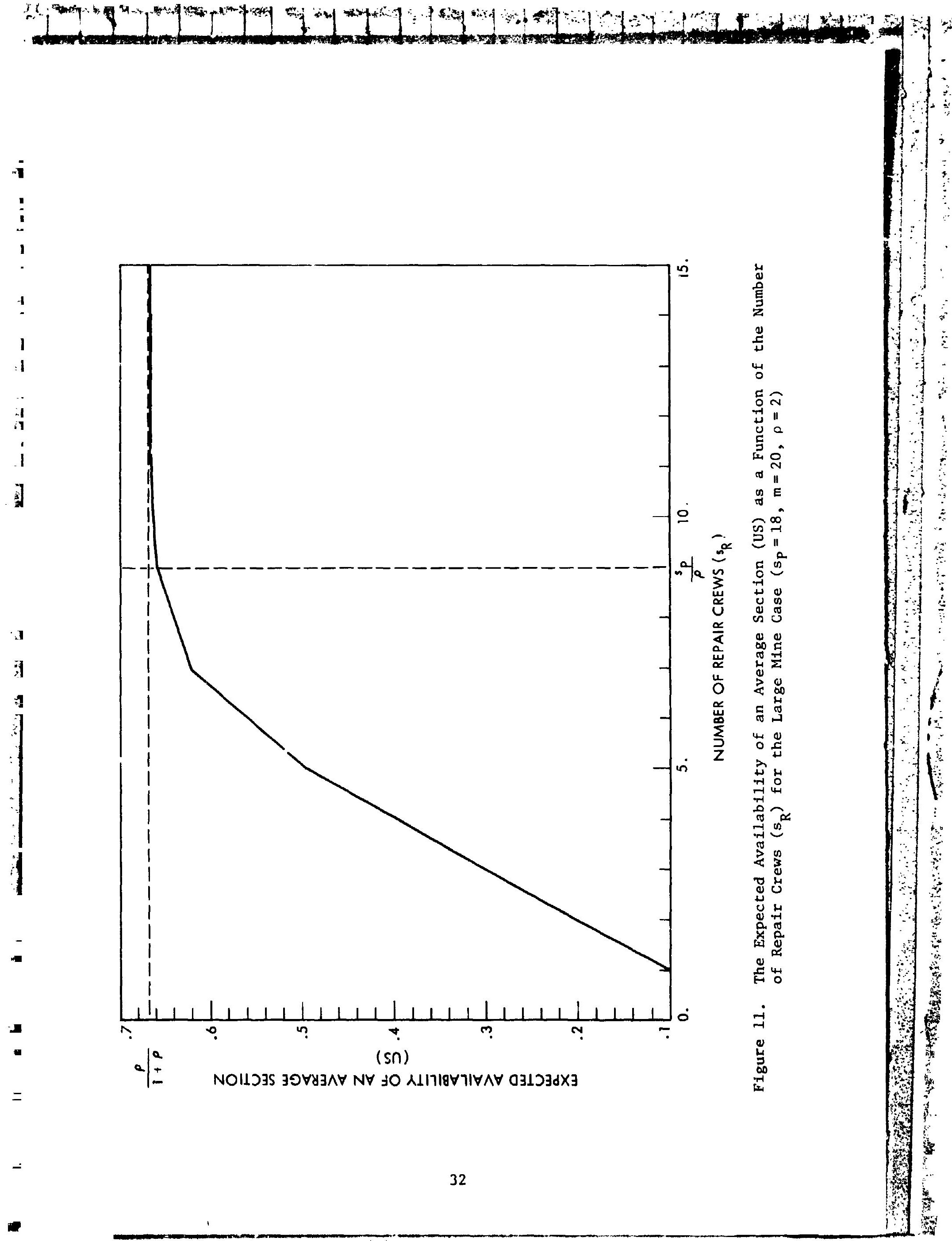




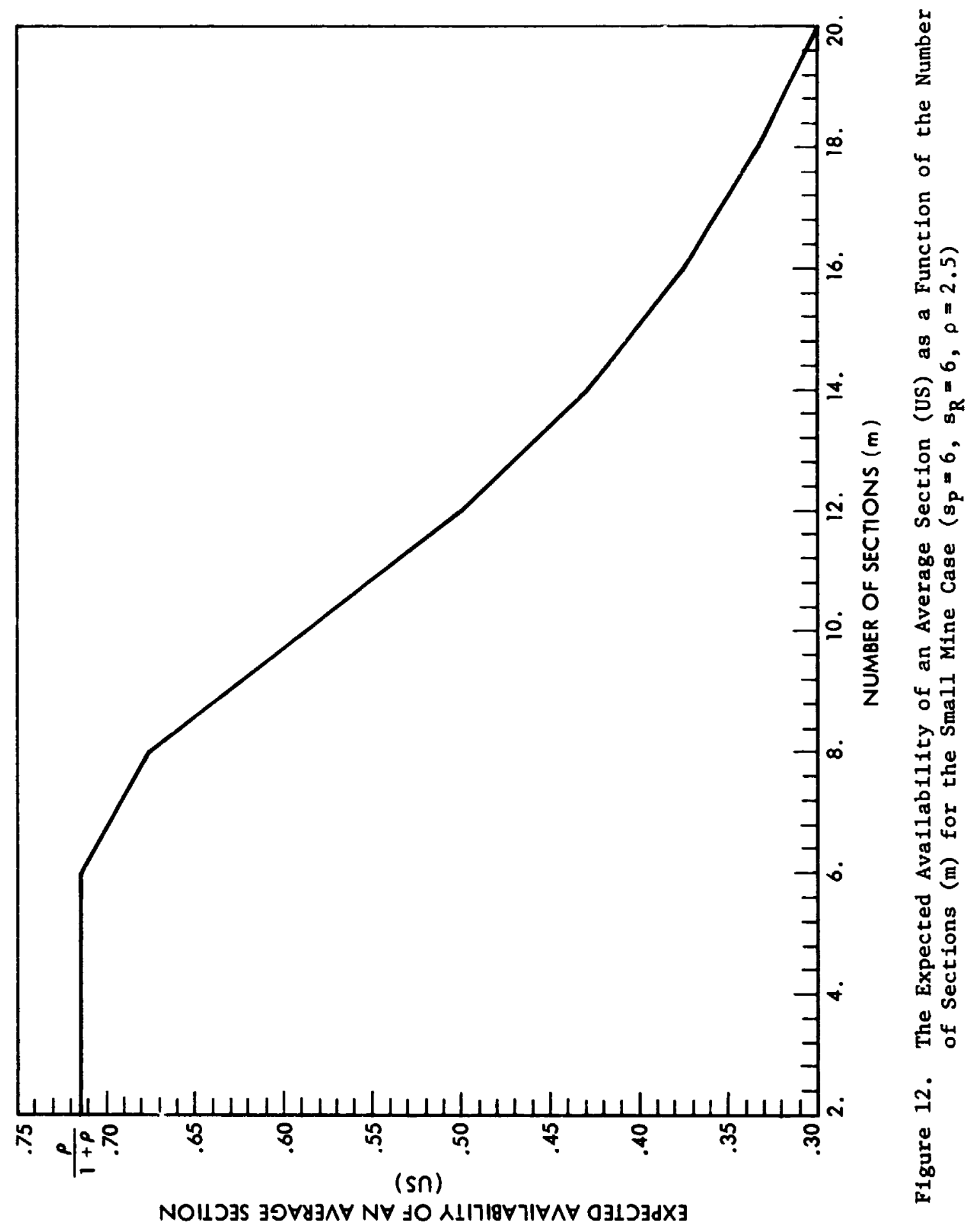




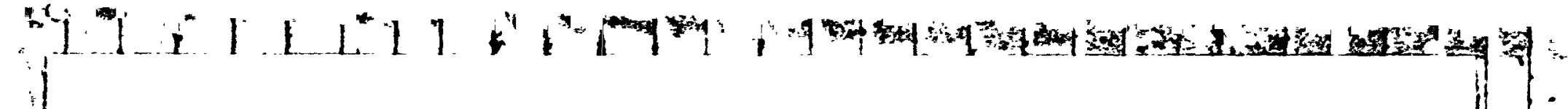

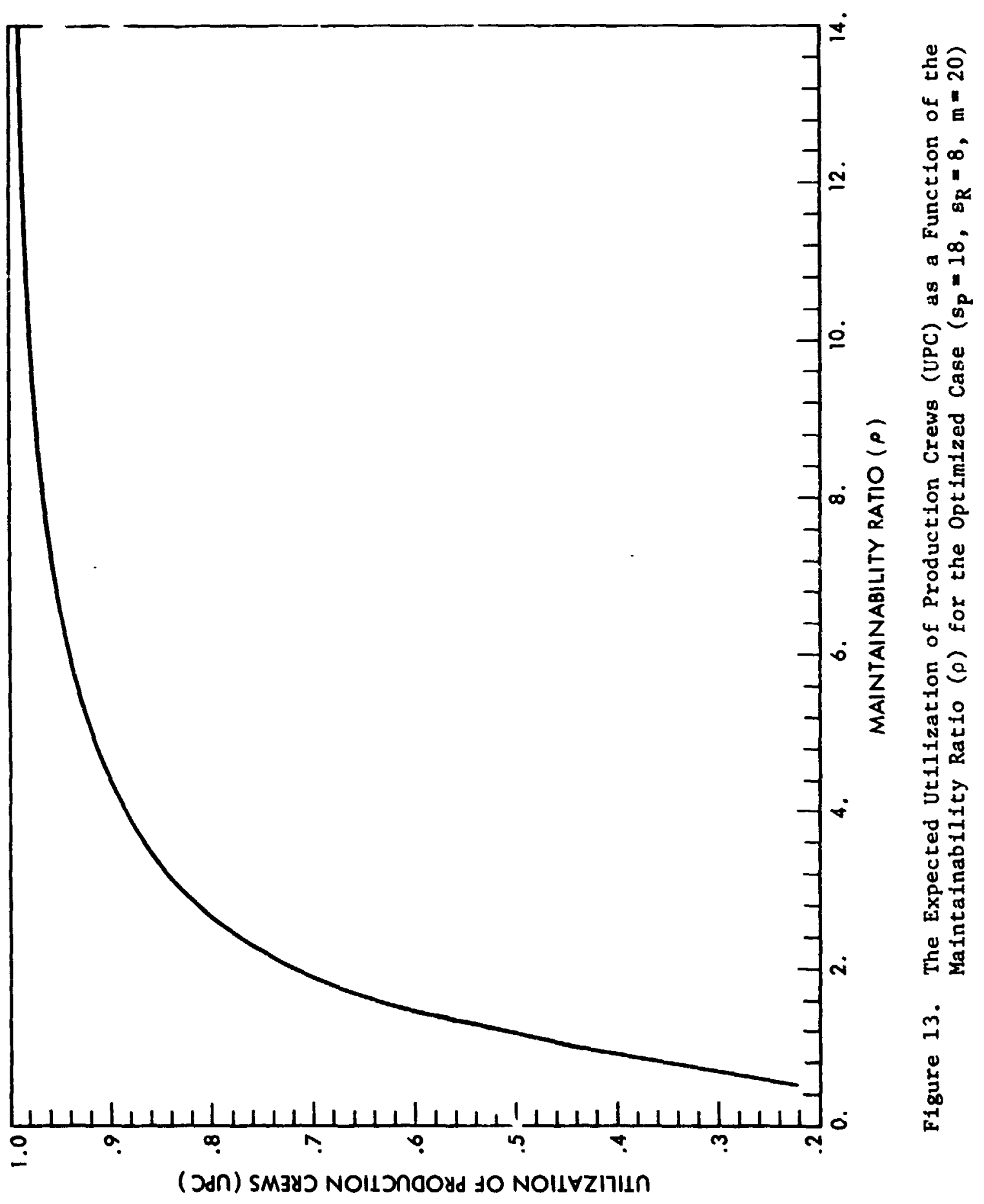




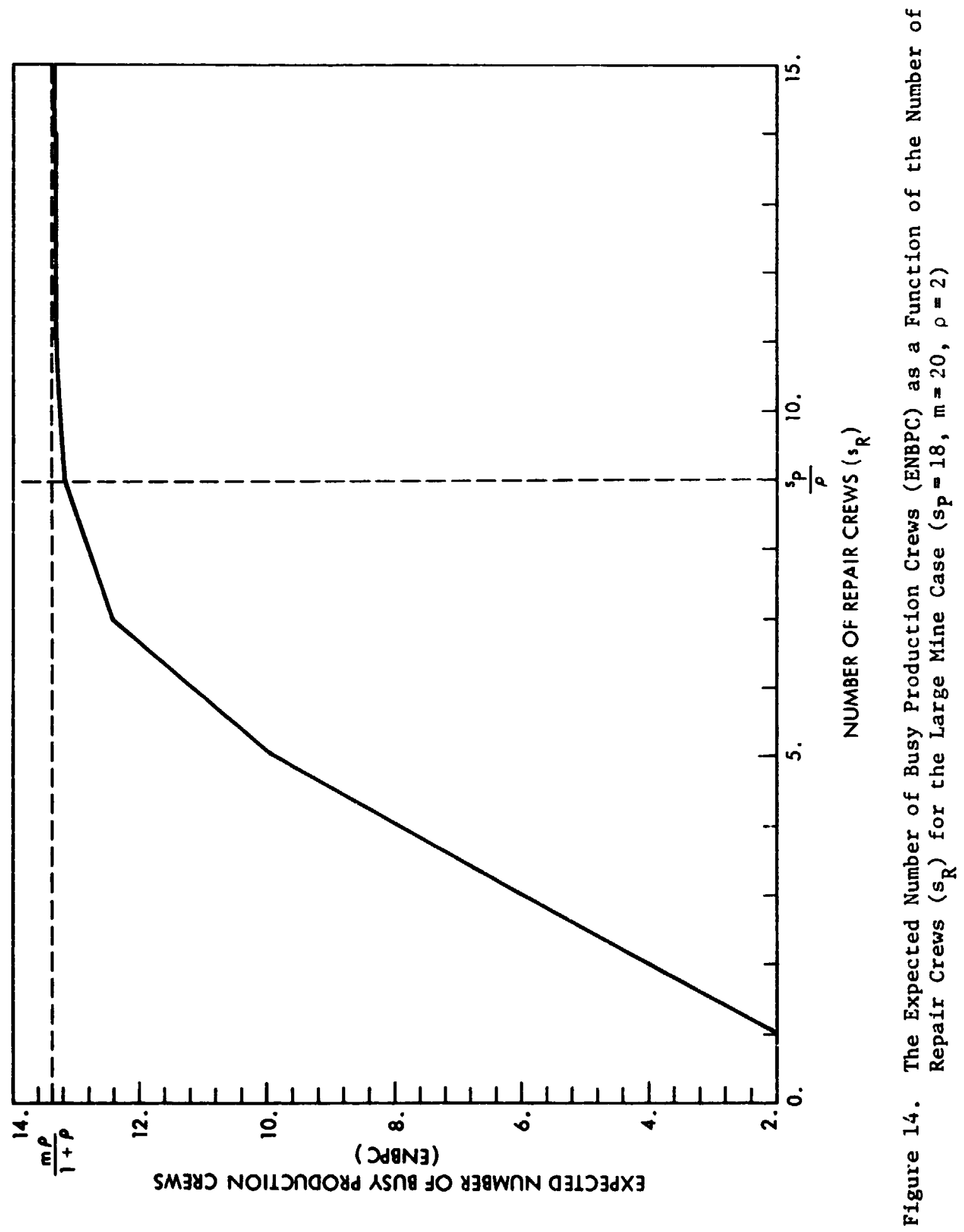

烈




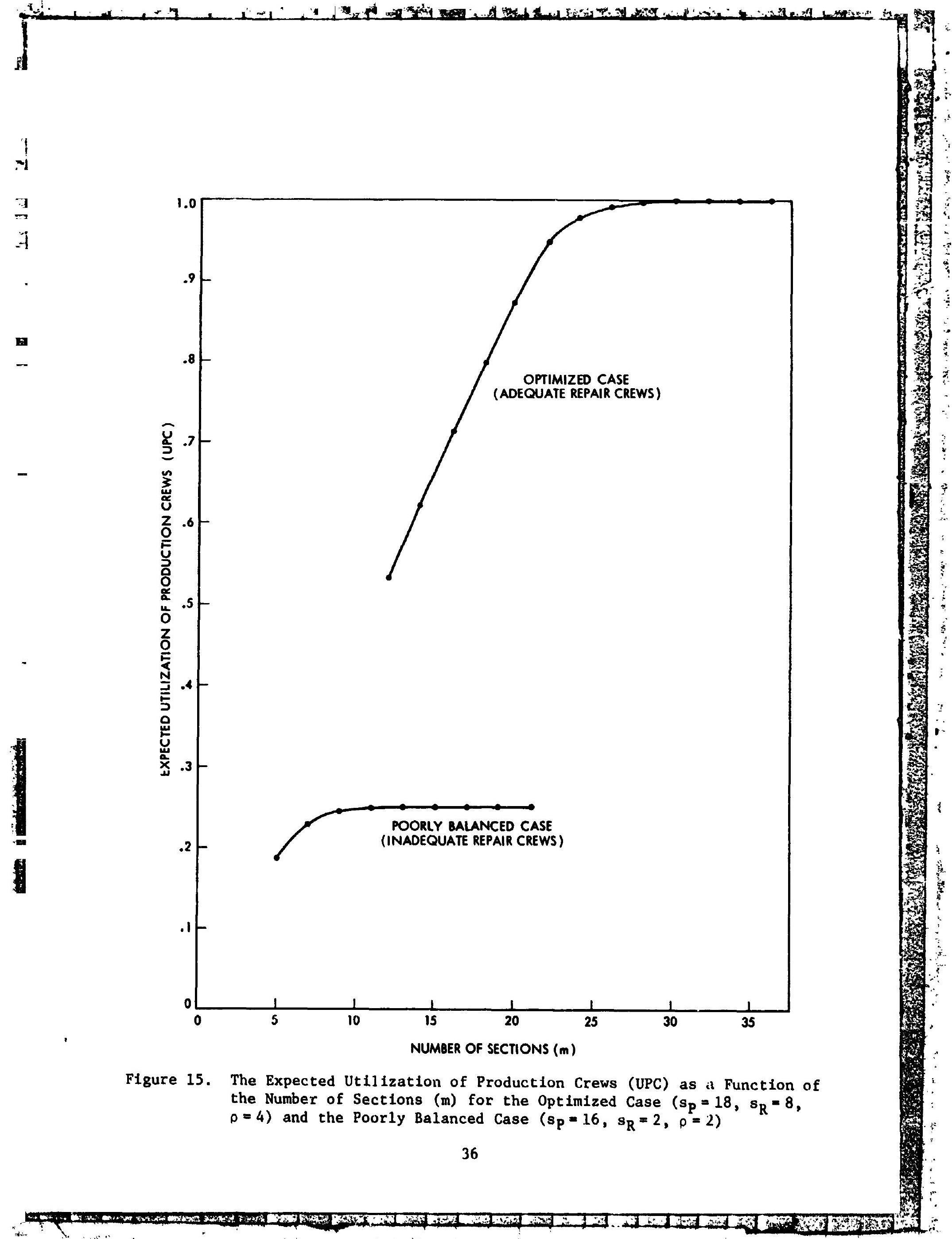



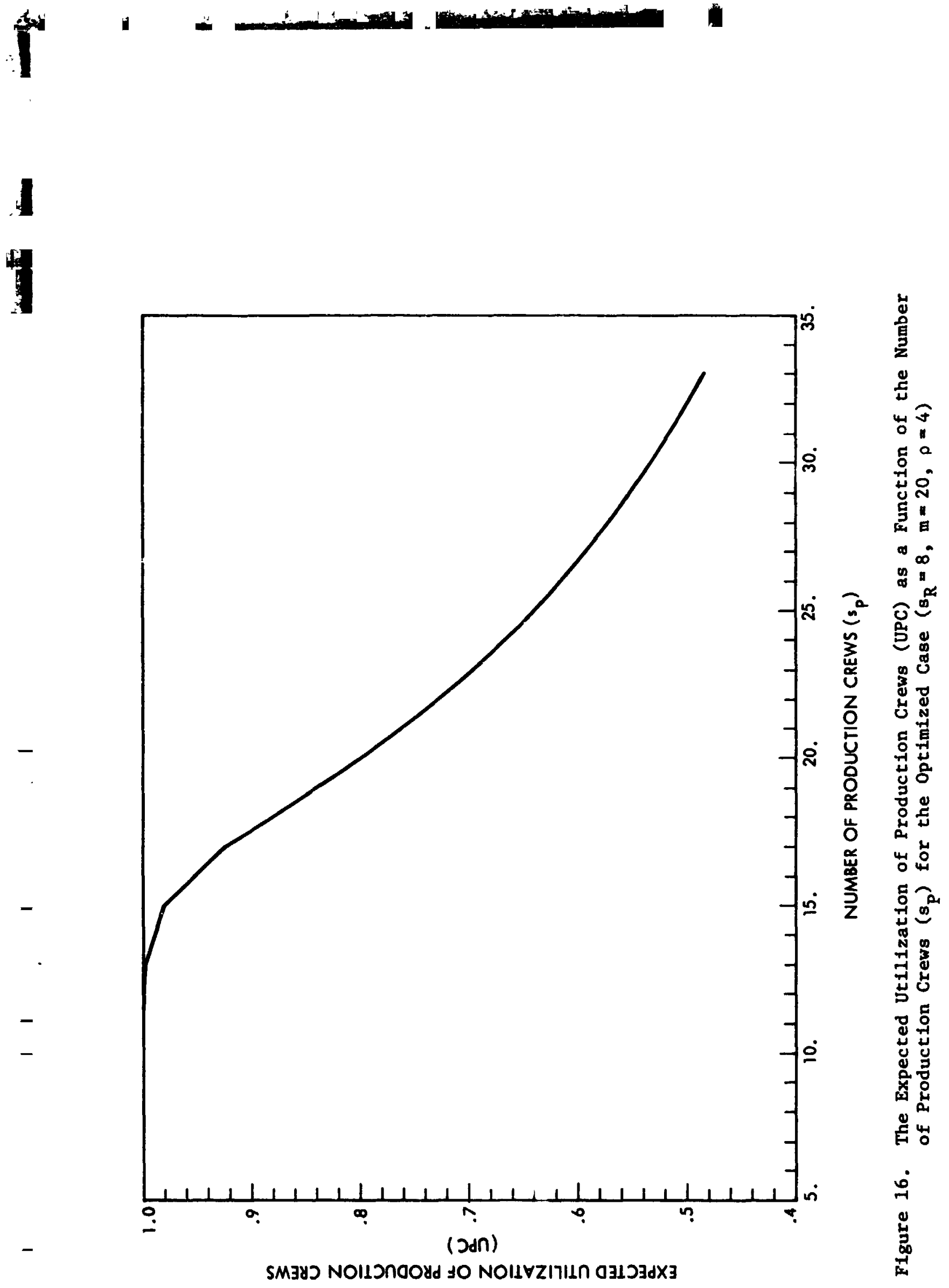


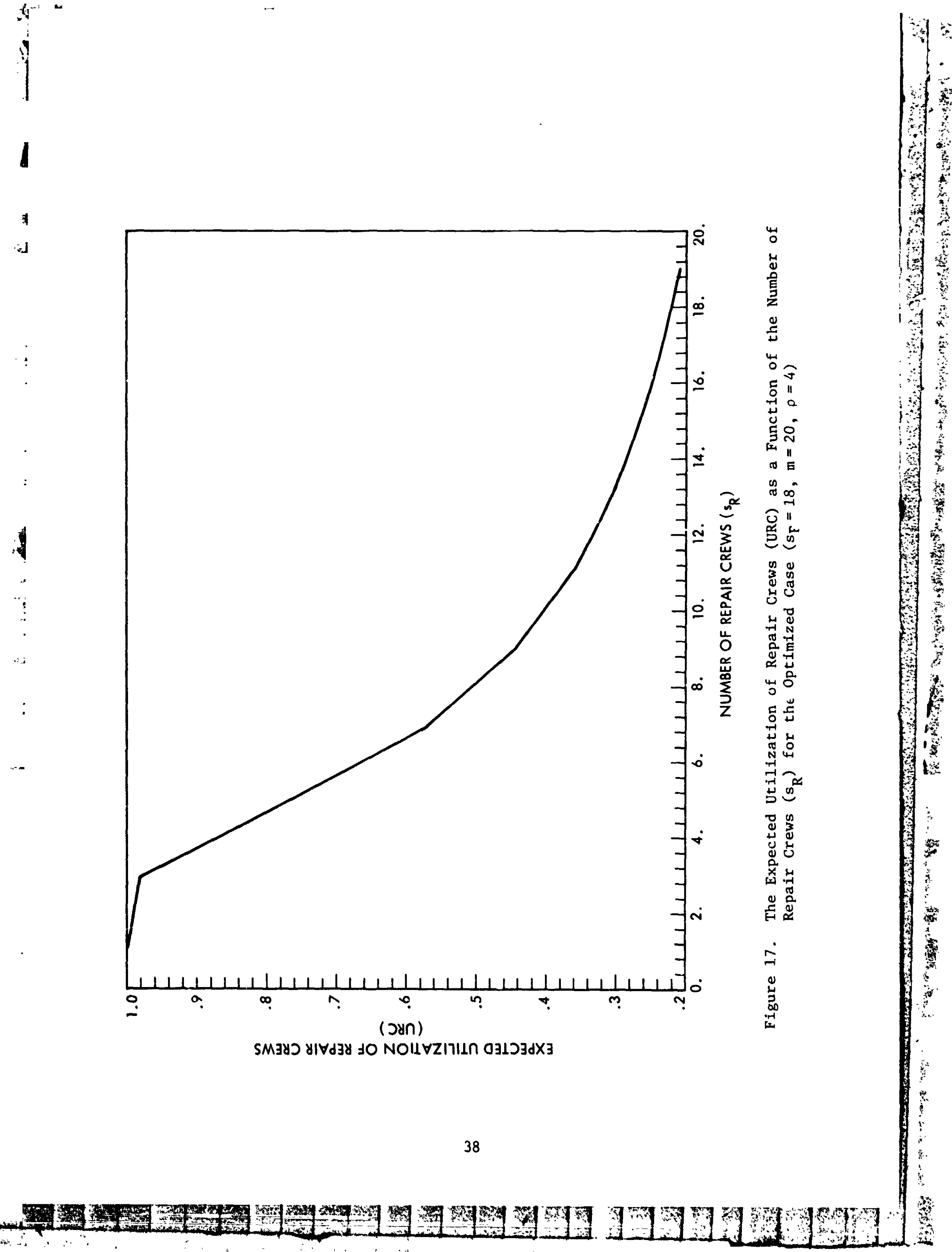




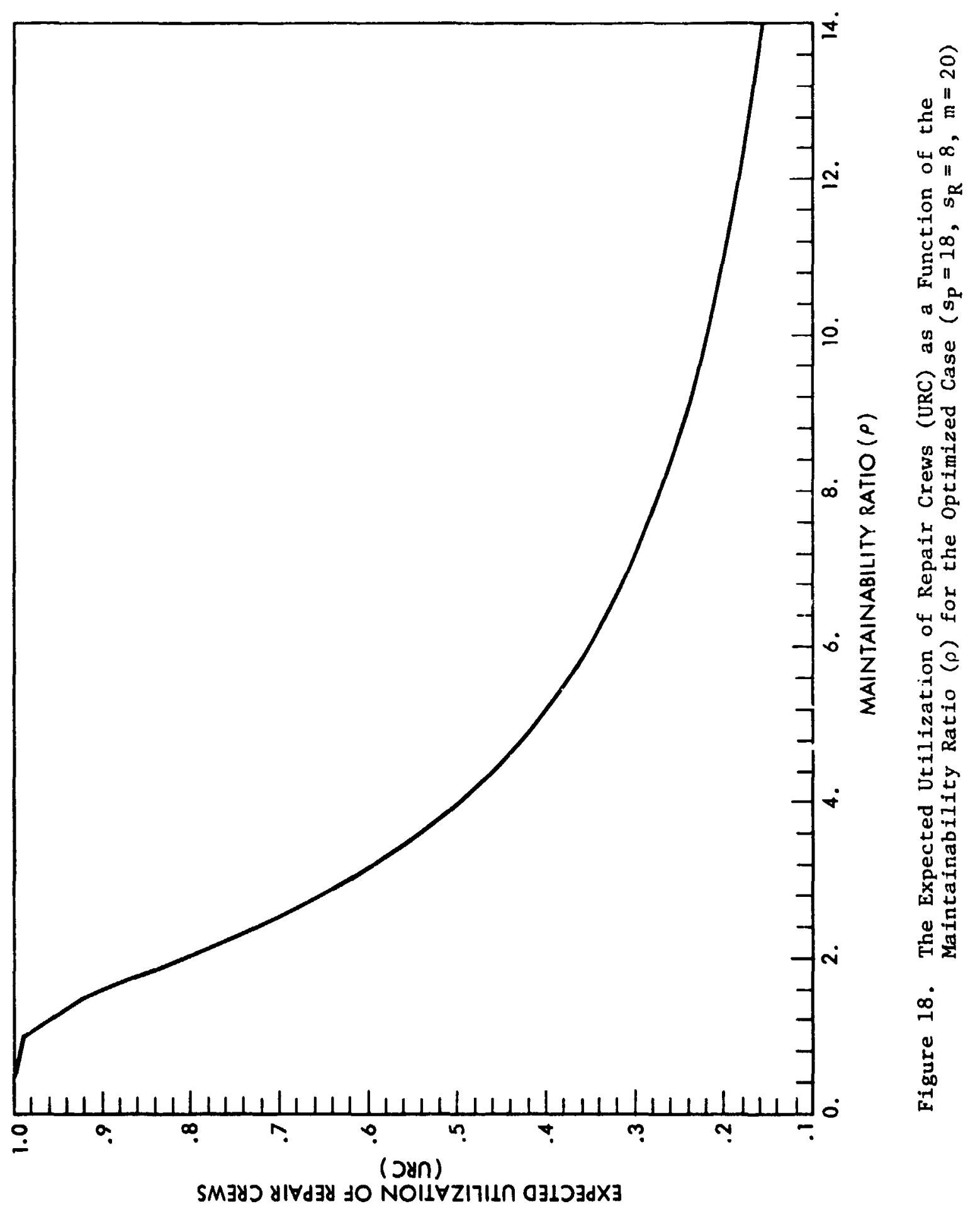




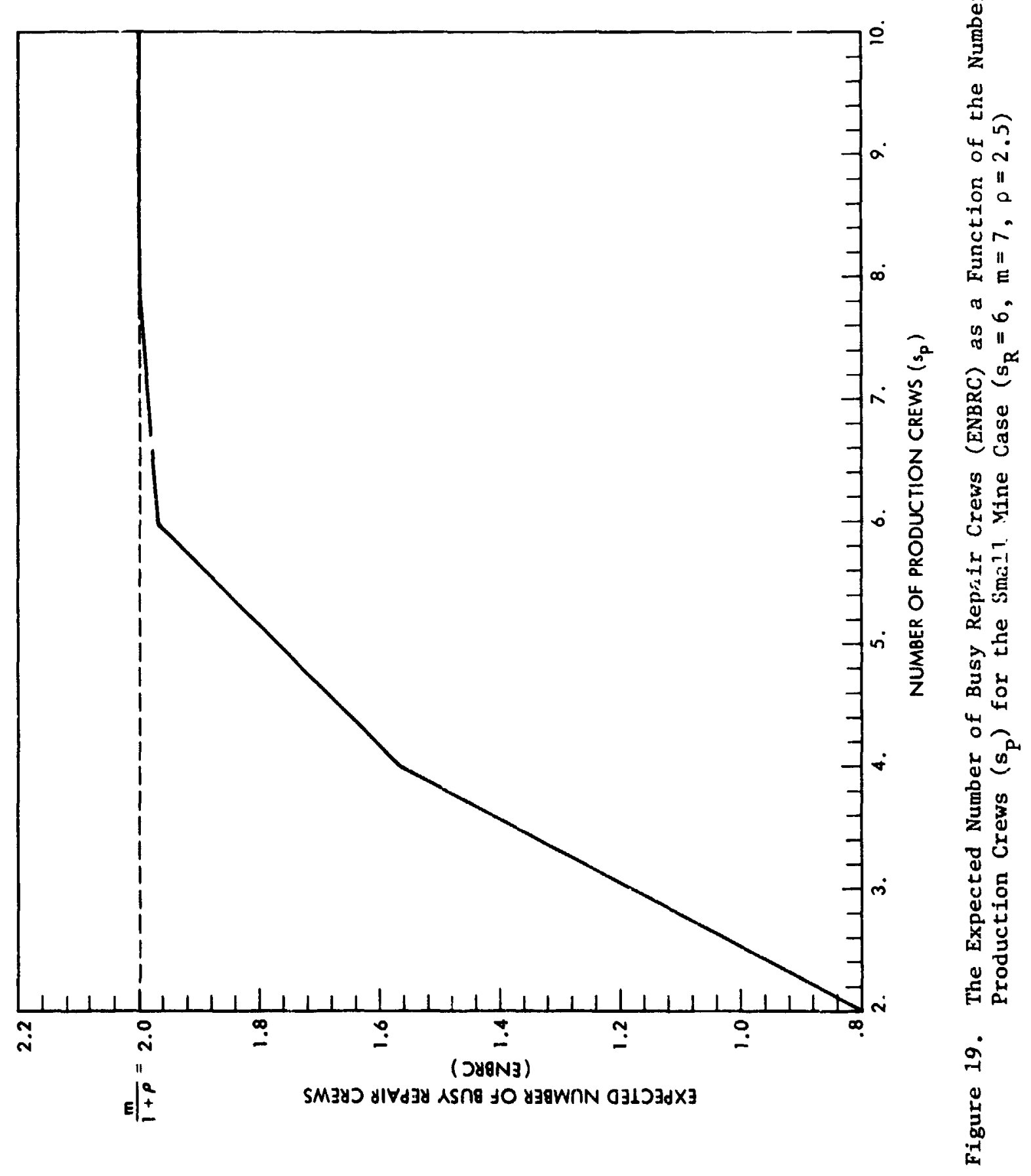




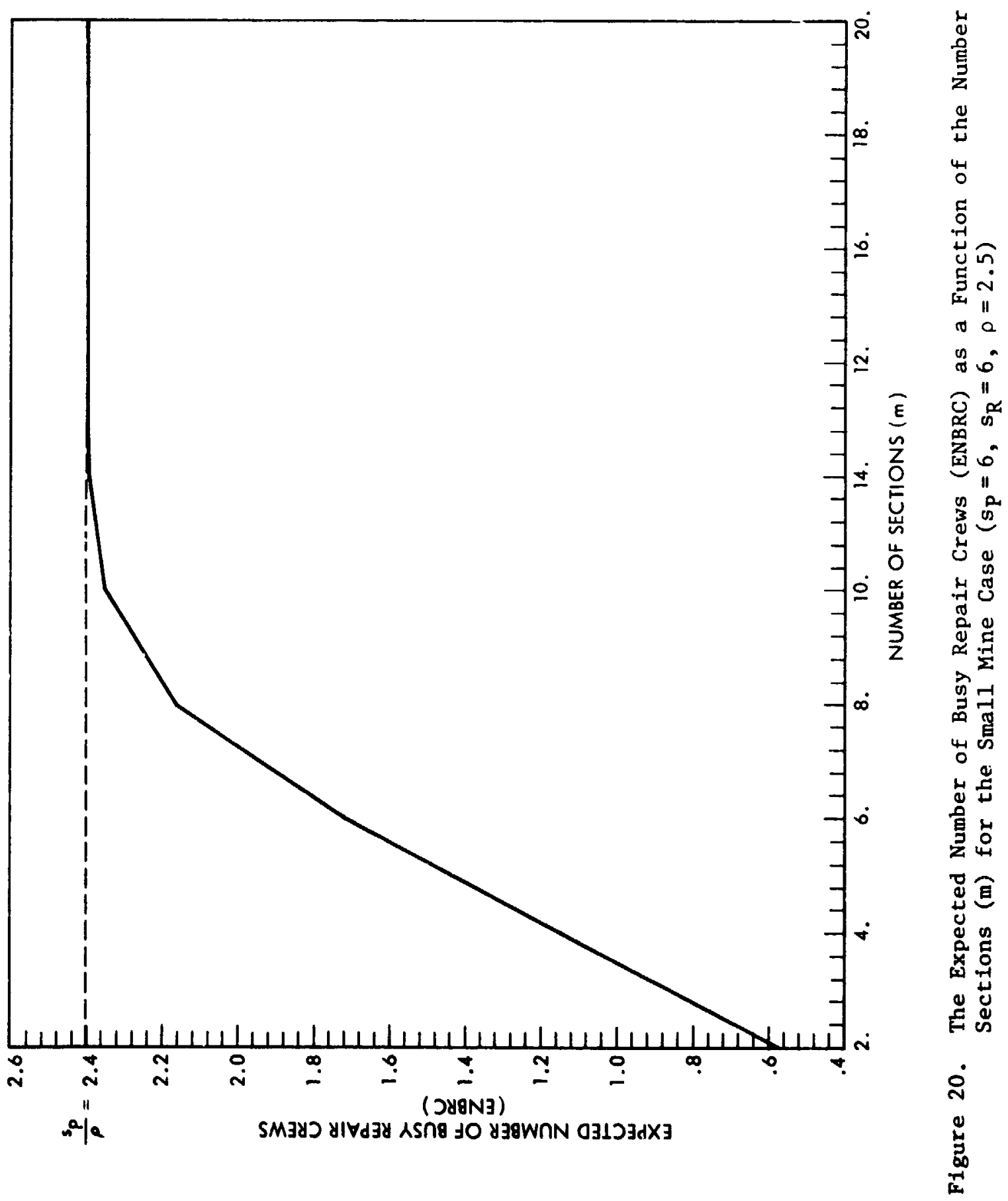




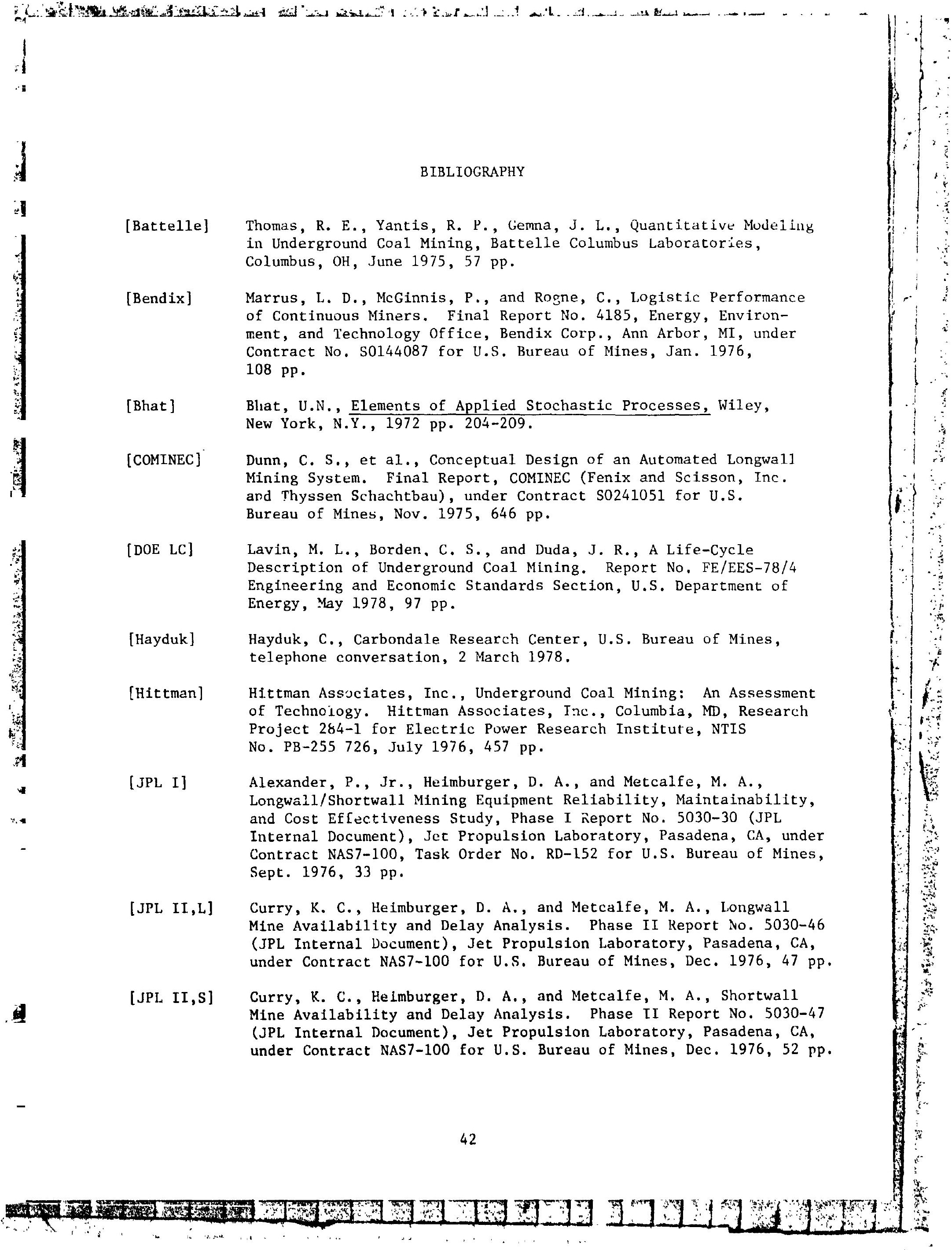




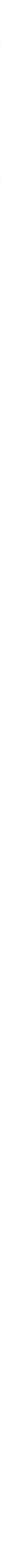

[JPL III] Curry, K. C., Lohman, G. M., and Metcalfe, M. A., Longwal1/ Shortwall Mine Equipment Availability and Delay Analysis, Final (Phase III) Report No. 5030-62 (JPL Internal Document), Jet Propulsion Laboratory, Pasadena, CA, under Contract NAS7-1n0 for U.S. Bureau of Mines, Feb. 1977, 65 pp. Report No. 77-19, Jet Propulsion Laboratory, Pasadena, CA, under Contract NAS7-100 Eua Bureau of Mines, Apri1 1977, 117 PP.

[Ketron] Douglas, W. J., Herhal, A. J,, Industrial Engineering Evaluation of Underground Conventional Mining Equipment. Final Report, Ketron, Inc., Wayne, PA, under Contract J0155203 for U.S. Bureau of Mines, July 1976, 188 pp. Probable Causes of Decreased Coal Mining Productivity (1969-1976). Contract Report J0177087, Division of Solid Fuels Mining and Preparation, U.S. Department of Energy, prepared by Management

Rau, J. G., Optimization and Probability in Systems Engineering, Van Nostrand Reinhold Company, New York, N.Y., 1970. 